\title{
Suportes cromatográficos e fases estacionárias para cromatografia líquida: preparo, evolução e tendências
}

\author{
Carlos Eduardo Domingues Nazario, Fernando Mauro Lanças* \\ Instituto de Química de São Carlos, Universidade de São Paulo - USP, CP 780, \\ Cep 13560-970, São Carlos, SP, Brasil \\ e-mail: flancas@iqsc.usp.br
}

\section{Resumo}

Desde o surgimento da instrumentação dedicada à HPLC, essa técnica analítica tem se destacado na separação e análise de uma grande variedade de compostos em diferentes campos de atuação. Nesse contexto, a área de pesquisa e desenvolvimento (P\&D) de suportes cromatográficos e de fases estacionárias para HPLC tem recebido atenção de pesquisadores, objetivando análises rápidas, colunas eficientes e seletividade adequada. Neste trabalho discutem-se os métodos utilizados no preparo de suportes cromatográficos para HPLC (principalmente os baseados em sílica) e as estratégias de modificação de sua superfície no preparo de fases estacionárias.

\section{Palavras-chave}

HPLC; suporte cromatográfico; sílica; fase estacionária.

\section{Chromatographic supports and stationary phases for liquid chromatography: preparation, evolution and trends}

\section{Abstract}

Since the development of instrumentation for HPLC, this analytical technique has been widely employed in the separations and analysis of a large variety of compounds in different fields. In this context, research and development $(\mathrm{R} \& \mathrm{D})$ area of chromatographic supports and stationary phases for HPLC have been receiving attention from researchers aiming the decrease in analysis time, increase column efficient and promote adequate selectivity. In this paper, we focused on the methods for the preparation of chromatographic supports for HPLC (especially silica-based materials) and strategies for modifying its surface in the preparation of stationary phases.

Keywords

HPLC; chromatographic support; silica; stationary phase. 


\section{Introdução}

O desenvolvimento da cromatografia líquida moderna como se conhece hoje iniciou-se na década de 1960 por dois grupos de pesquisa: Csaba Horváth, nos Estados Unidos, e Josef Huber, na Europa. Esses pesquisadores conduziram estudos voltados para o desenvolvimento de um sistema instrumental de cromatografia líquida hoje conhecida como cromatografia líquida de alta eficiência (HPLC) ${ }^{[1]}$. Desde o surgimento da instrumentação apropriada, a HPLC tem se destacado rapidamente como uma técnica analítica eficiente na área química, farmacêutica, alimentar, ambiental e biológica. Em HPLC, diferentes modos de separação estão disponíveis tais como modo normal, reverso, iônico, exclusão, interação hidrofílica, quiral, bioafinidade etc ${ }^{[2,3]}$. A base para o desenvolvimento dos modos de separação em HPLC é o suporte cromatográfico presente no interior da coluna. Assim, pesquisas voltadas para o desenvolvimento de suporte cromatográfico e fases estacionárias para HPLC têm sido conduzidas por pesquisadores acadêmicos e da indústria com o objetivo de aprimorar a seletividade e diminuir o tempo de análise sem comprometer a resolução cromatográfica.

\section{Síntese de suporte cromatográfico}

Um bom suporte cromatográfico para HPLC deve possuir algumas características fundamentais como ser mecanicamente estável, ou seja, suportar altas pressões exigidas no sistema HPLC, possuir grande concentração de grupos ativos na superfície, a fim de promover melhor desempenho cromatográfico, ser inerte em relação aos compostos a serem analisados, possuir área superficial e diâmetro de poros adequados (fator dependente da aplicação) $)^{[4]}$.
Em cromatografia líquida, os suportes cromatográficos podem ser baseados em polímeros inorgânicos, orgânicos ou híbridos ${ }^{[5]}$. Entre os polímeros inorgânicos pode-se destacar o óxido de silício (sílica), que é o suporte mais utilizado nas separações cromatográficas ${ }^{[6]}$. A sílica apresenta-se em unidades tetraédricas $\left(\mathrm{SiO}_{4}\right)$ aleatórias unidas por grupos siloxanos e sua superfície apresenta grupos silanois ${ }^{[7,8]}$. O destaque da sílica como suporte cromatográfico em HPLC ocorre devido às suas características favoráveis como, por exemplo, boa resistência mecânica, estabilidade química térmica, área superficial e estrutura de poros controláveis e grupos silanois suscetíveis a posteriores modificações no preparo de diferentes fases estacionárias ${ }^{[9-14]}$.

As características do suporte cromatográfico baseado em sílica são extremamente dependentes da estratégia utilizada para o seu preparo. Entre as metodologias de síntese de sílica podem-se destacar o método de gelificação das soluções de sal de silicato (sil-gel), o método de hidrólise de organossilanos (sol-gel) e o método de agregação controlada de sílica coloidal estável. O termo sol é utilizado para definir uma dispersão de partículas coloidais (diâmetro entre 1-100 nm), enquanto o termo gel é caracterizado como um sistema formado por estruturas rígidas das partículas coloidais ou de cadeias poliméricas que imobiliza a fase líquida nos seus interstícios ${ }^{[15]}$.

\subsection{Processo sil-gel}

Pela rota sílica gel (também chamada de sil-gel) usualmente se utiliza o silicato de sódio como material de partida. A descoberta da sílica gel foi realizada por Thomas Graham (1861): ele preparou a sílica a partir de uma mistura de uma solução aquosa de silicato de sódio, normalmente preparada através do aquecimento de areia e soda cáustica a temperatura elevada ${ }^{[7]}$, que depois sofre um processo de hidrólise com 
a adição do ácido clorídrico, formando o ácido silícico. Posteriormente, ocorre a reação de condensação do ácido silícico formando dímeros, trímeros e, consequentemente, uma rede polimérica de ácido silícico (Figura 1). Nesse processo, a rede polimérica continua crescendo e formando partículas esféricas primárias de alguns angstrons de diâmetro (Figura 2a). As partículas primárias continuam a aumentar de tamanho e, posteriormente, sofrem condensação através dos grupos silanois presentes em sua superfície (Figura 2b). Como resultado, as partículas primárias ficam aderidas umas às outras (aglomeração) e a solução começa o processo de gelificação para formar o hidrogel (Figura 2c).
Após a formação do hidrogel, o material sintetizado é submetido a um período de envelhecimento no qual as partículas primárias de sílica continuam o processo de polimerização. Essa etapa é importante, pois confere resistência mecânica ao material final. Em seguida o hidrogel passa para a etapa de desidratação (secagem), na qual é transformado em xerogel ${ }^{[7]}$.

A característica final da sílica sintetizada através desta rota é extremamente dependente das condições reacionais (concentração dos reagentes, temperatura da reação, $\mathrm{pH}$ da solução, tempo e condições de envelhecimento e processo de secagem) e, muitas vezes, difícil de controlar e reproduzir. A influência do $\mathrm{pH}$ no tempo de gelificação está representada na Figura 3.

\section{Hidrólise}

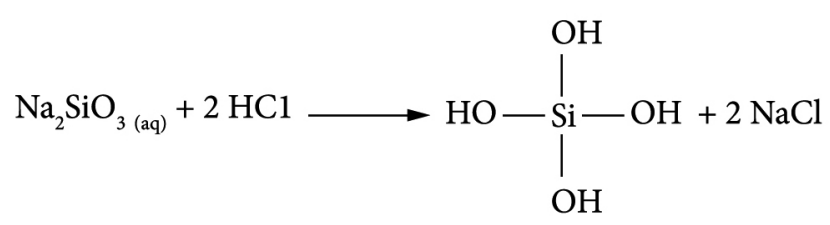

Ácido silícico

\section{Condensação}

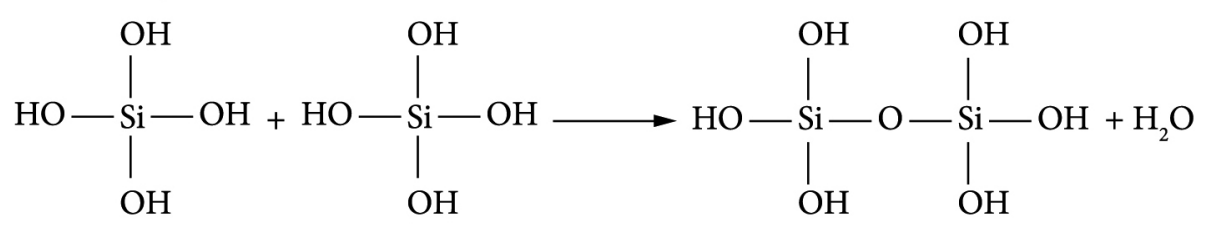<smiles>O[Si](O)(O)O[C@H]1O[Si](O[Si](O)(O)O)(O[Si](O)(O)O)O[C@@H]1O[Si](O)(O)O[Si](O)(O)O</smiles>

Figura 1 Etapas do processo sil-gel: hidrólise e condensação. 


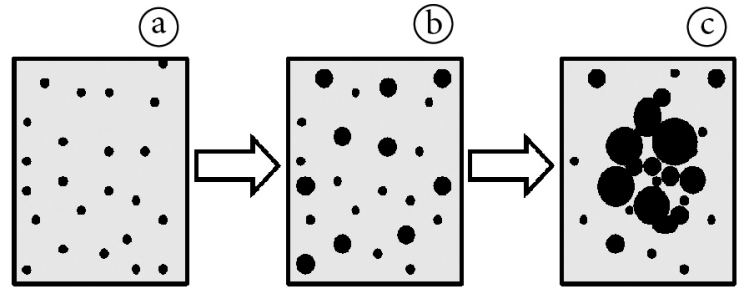

Figura 2 Representação da formação da sílica gel: (a) formação das partículas primárias; (b) aumento de tamanho das partículas primárias; e (c) formação do hidrogel.

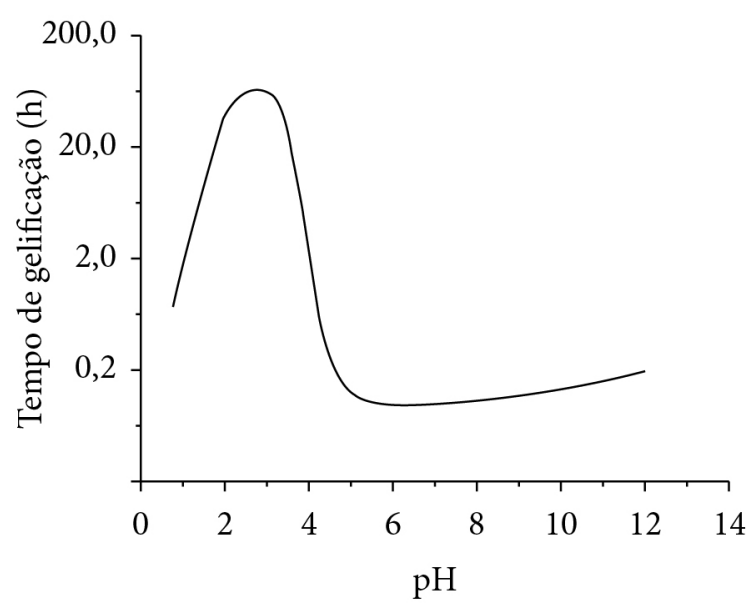

Figura 3 Influência do pH no tempo de gelificação no processo sil-gel.

Pode-se observar que em baixos valores de $\mathrm{pH}$, o tempo de gelificação aumenta rapidamente com o aumento do $\mathrm{pH}$ (próximo a 2). $\mathrm{Na}$ faixa de $\mathrm{pH}$ entre 2 e 4 , a solução é estável e muitas horas são necessárias para promover a formação do hidrogel. Em contrapartida, se o pH da solução é ajustado entre 4 e 8 , a solução se torna instável e a formação do hidrogel ocorre em poucos minutos. Acima de $\mathrm{pH} 8$, o tempo de gelificação começa a aumentar novamente e ocorre a competição com a quebra da rede polimérica da sílica, devido à sua solubilização ${ }^{[7]}$.

Partículas de sílica formadas na faixa de pH entre 1-4 apresentam grande área superficial (aproximadamente $800 \mathrm{~m}^{2} \mathrm{~g}^{-1}$ ). Em contrapartida, na medida em que o $\mathrm{pH}$ é aumentado de 4 para 8 ocorre uma diminuição dos valores de área superficial $\left(800 \mathrm{~m}^{2} \mathrm{~g}^{-1}\right.$ para $\left.200 \mathrm{~m}^{2} \mathrm{~g}^{-1}\right)$. De forma geral, a área superficial das partículas de sílica é inversamente proporcional às dimensões das partículas primárias provenientes da polimerização do ácido silícico. Como resultado, as partículas primárias são relativamente menores quando preparadas em $\mathrm{pH}$ entre 1-4, quando comparadas com a faixa de $\mathrm{pH}$ 4-8.

Quando a solução de silicato de sódio com o pH ajustado é submetida a agitação magnética ocorre o fenômeno chamado maturação de Otswald (também conhecido como envelhecimento de Otswald). Esse processo consiste no aumento do diâmetro de partículas a custa de partículas primárias com diâmetro menor. Adicionalmente, o processo de maturação/envelhecimento do gel formado leva ao aumento do tamanho das partículas primárias. Além disso, logo após a formação do gel, o mesmo não apresenta rigidez e, durante o processo de maturação por alguns dias, reações de condensação das partículas primárias continuam ocorrendo e o hidrogel se torna firme e com boa resistência mecânica ${ }^{[7]}$.

O processo de lavagem do hidrogel após o envelhecimento também altera as características finais da sílica. Estudos demonstram que a lavagem do hidrogel com solução ácida $(\mathrm{pH}=3)$ promove uma diminuição da área superficial do polímero quando comparada com a lavagem com água em $\mathrm{pH}=6,5$. Além disso, a imersão do hidrogel em diferentes solventes também promove alterações no material sintetizado. Após todas essas etapas, o hidrogel é submetido a aquecimento para se transformar em xerogel. Para serem utilizadas como suporte cromatográfico em LC, as partículas do xerogel são trituradas e separadas em faixas de diâmetros de partículas com aplicabilidade em LC. Ajustes nas condições sintéticas devem ser realizados de acordo com os parâmetros desejados para o polímero final. 
Esse método permite obter partículas irregulares classificadas como sílica gel tipo A por utilizar precursor de baixa pureza e, portanto, apresentar maior quantidade de metais $(\mathrm{Na}, \mathrm{Ca}$, $\mathrm{Fe}, \mathrm{Al}, \mathrm{Mg}, \mathrm{Cu}, \mathrm{Zn})^{[16,17]}$. Dessa forma, um tratamento dos materiais de partida com resina catiônica antes do preparo do hidrogel ${ }^{[18]} \mathrm{e} / \mathrm{ou}$ tratamento pós-síntese em meio ácido ${ }^{[19]}$ promovem uma maior homogeneidade na superfície da sílica. Adicionalmente, esse processo diminui a acidez dos silanois devido à presença de metais incorporados na rede polimérica da sílica. Além da utilização do silicato de sódio sólido ${ }^{[20]}$ ou em solução (waterglass) ${ }^{[21]}$ como material de partida no processo sil-gel, na literatura encontram-se trabalhos descrevendo outras fontes de sílica de baixo custo, tais como areia ${ }^{[8]}$, casca de arroz ${ }^{[22]}$ e argila ${ }^{[23]}$. Pode-se destacar a utilização desses materiais como suporte em técnicas de preparo de amostra.

\section{$2.2 \bigcirc$ processo sol-gel}

O processo sol-gel é uma segunda abordagem empregada para preparar partículas de sílica. Nessa rota sintética geralmente utilizam-se precursores alcoxissilano (tetrametoxissilano (TMOS) ou tetraetoxissilano (TEOS)) dissolvidos em álcool. Posteriormente, com a adição de água e catalisador (ácido ou básico) ocorre a reação de hidrólise e condensação. É importante ressaltar que a hidrólise dos alcoxissilanos ocorre com maior eficiência e rapidez quando catalisadores são utilizados no processo. Normalmente, as reações de hidrólise e condensação ocorrem simultaneamente, assim que os reagentes são misturados. A reação de hidrólise leva à formação de grupos silanois e as reações de condensação levam à formação de ligações siloxano. A Figura 4 ilustra as reações químicas que ocorrem durante a transformação sol-gel. A reação de condensação possui um mecanismo complexo, pois se inicia antes do término da reação de hidrólise.

No processo sol-gel, a sílica obtida é classificada como do tipo B por apresentar maior pureza em relação à sílica tipo $\mathrm{A}$ (concentração de metais $<0,3 \%)$. As características finais da sílica também são dependentes das condições experimentais de síntese (concentração dos precursores, velocidade de agitação, temperatura reacional, natureza do catalisador). Um método amplamente conhecido para a obtenção de partículas esféricas e monodispersas de sílica é o método de Stöber, o qual se baseia na hidrólise e condensação de alcoxissilano em uma solução contendo água, álcool e amônia, formando partículas de hidrogel que, posteriormente, são calcinadas para aumentar a estabilidade do material ${ }^{[24]}$. Normalmente, as partículas obtidas nesse processo são consideradas não porosas e possuem diâmetro em escala nanométrica. $\mathrm{O}$ aumento no diâmetro médio pode ser obtido através do método de crescimento de partícula, o qual consiste em adicionar o precursor da sílica na suspensão das partículas.

Segundo Chang et al. ${ }^{[25]}$, as partículas de sílica começam a aumentar de tamanho quando a concentração de TEOS no sistema alcança o nível saturado $\left(\mathrm{C}_{\mathrm{S}}\right)$. Entretanto, se a concentração de TEOS ultrapassar um valor limite de saturação $\left(\mathrm{C}_{\mathrm{S}}^{*}\right)$ ocorrem novas nucleações, comprometendo a monodispersão das partículas. Chou e Chen ${ }^{[26]}$ avaliaram o aumento no tamanho dos materiais, relacionando a velocidade de geração de novas nucleações e a velocidade de consumo do TEOS no crescimento de partículas. Se a velocidade de consumo do TEOS for maior que a de formação de novas partículas, ocorrerá aumento no diâmetro das partículas sem o surgimento de novas nucleações (secundárias). Contudo, se o inverso ocorrer, aparecerão novas nucleações (Figura 5). 


\section{Hid rólise ácida/básica}

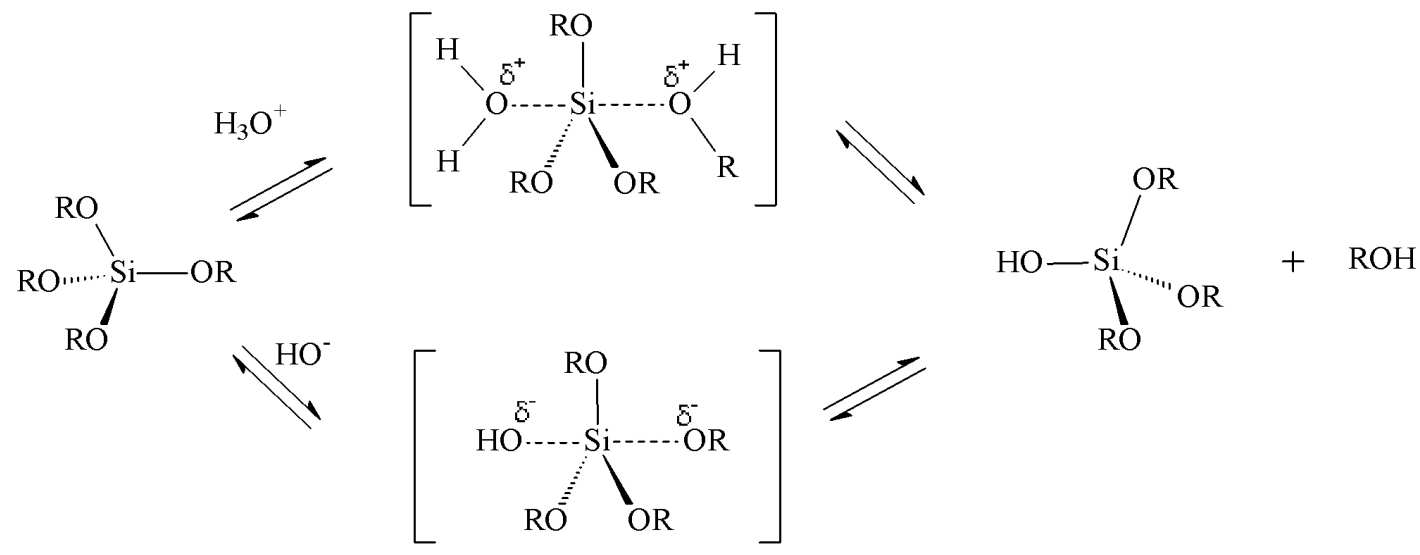

\section{Condensação}<smiles>[R][Si]([R20])([R])O</smiles>

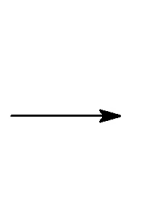<smiles>[R][Si]([R20])([R6])O[Si]([R20])([R20])[R]</smiles><smiles>[R20][Si]([R20])([R6])O[Si]([R20])([R20])O</smiles><smiles>[R][Si](O)(O)O[Na]</smiles>

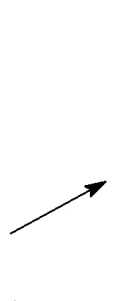<smiles>[R]O[Si]1([R2])O[Si]([R20])([R20])O[Si]([R2])(OC)O1</smiles><smiles>[R20][Si](O)(O)OCC</smiles>

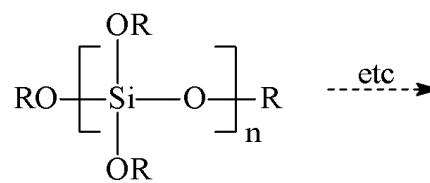<smiles>C[12CH2]</smiles><smiles>[R6][Si](O[Si](C)(C)C)(O[Si](C)(C)C)O[Si](C)(C)C</smiles>

Figura 4 Etapa de hidrólise e condensação no processo sol-gel.

Uma forma de obter partículas porosas empregando o método de Stöber é incorporando, no processo sintético, compostos formadores de poros. Nesse procedimento, moléculas volumosas são utilizadas como template de poros e incorporadas na rede polimérica de sílica. Assim, após sua remoção por calcinação, a partícula de sílica apresenta maior porosidade. Unger et al. ${ }^{[27]}$ realizaram trabalhos empregando alquilaminas (dodecilamina e hexadecilamina) para produzir poros nas partículas de sílica sintetizadas pelo método de Stöber modificado. 


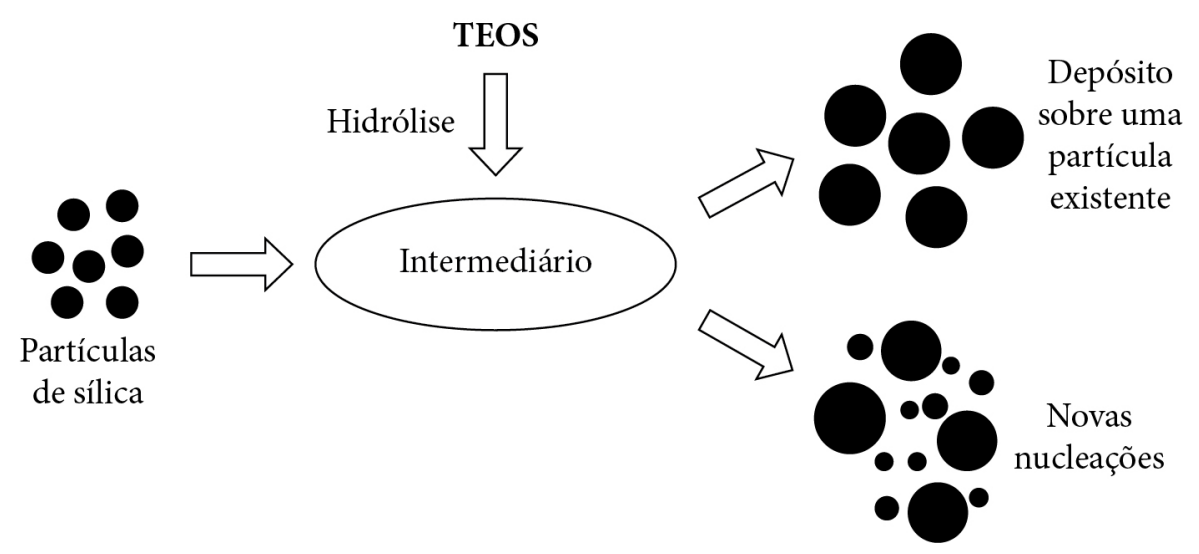

Figura 5 Esquema da geração e consumo do intermediário sintético no processo de crescimento de partícula.

Similarmente, outros trabalhos têm mostrado bons resultados ao utilizar cloreto de hexadeciltrimetilamônio $(\mathrm{CTAC})^{[28]}$ ou brometo de hexadeciltrimetilamônio $(\mathrm{CTAB})^{[29]}$ como surfactante porogênico. Após sua síntese, o material é submetido a calcinação $\left(500^{\circ} \mathrm{C}-600{ }^{\circ} \mathrm{C}\right)$ para remoção da cadeia orgânica e geração dos poros na partícula de sílica. Com esse procedimento, materiais com mesoporos são usualmente sintetizados. Adicionalmente, trabalhos têm relatado que o tamanho dos poros pode ser expandido para a faixa de meso e macroporos através do tratamento das partículas de sílica com hidróxido de sódio, carbonato de sódio ou agentes complexantes orgânicos em temperatura elevada. Pode-se considerar que esse processo de adequação dos poros está relacionado e fundamentado no processo de maturação de Ostwald ${ }^{[29,30]}$.

Nesse contexto, em 1992 foi desenvolvida a sílica mesoporosa do tipo MCM-X (Mobile Crystalline Material) utilizando-se alquilamônio como surfactante em meio básico, por pesquisadores da Mobil Corporation. Em 1998, utilizando surfactantes catiônicos em meio ácido, Zhao et al. sintetizaram SBA-X (Santa Barbara Amorphous), sílica mesoporosa, utilizando copolímero tribloco como molde. Sílica com mesoporos altamente ordenados (SBA-15 e SBA16) foi obtida utilizando-se surfactantes não iônicos. Em 2000, outros materiais denominados MSU-X (Michigan State University) foram obtidos utilizando-se surfactantes não iônicos em pH neutro; contudo sua estrutura é mais desorganizada em comparação com a das outras sílicas mesoporosas. Dessa forma, a sílica mesoporosa é um material interessante como suporte cromatográfico em HPLC devido à sua grande área superficial $\left(1.000 \mathrm{~m}^{2} \mathrm{~g}^{-1}\right)$ e estrutura organizada de $\operatorname{poros}^{[31,32]}$.

\section{$2.3 \bigcirc$ processo de agregação controlado}

Uma terceira abordagem para a preparação de partículas de sílica porosa para LC é o método de agregação controlado. Nessa rota sintética pode ser utilizada a agregação reativa ou a agregação de gotículas (gotas) dispersas.

\subsection{1 $\bigcirc$ processo de agregação reativa}

Esse processo foi desenvolvido por Iler e McQueston em 1977, que o chamaram de coacervação (coacervation). Nesse procedimento, uma solução aquosa e estável de partículas de sílica coloidal (centenas de angstrons) é misturada com monômeros orgânicos miscíveis na solução. Após o processo de polimerização dos monômeros, as partículas coloidais de sílica são 
microencapsuladas em agregados esféricos na matriz polimérica orgânica (Figura 6). Por exemplo, ureia e formaldeído podem ser adicionados a uma solução coloidal em que, após ajuste do pH em faixas ácidas, ocorre o encapsulamento das partículas de sílica em escala nanométrica para a formação de partículas na escala micrométrica com polímero orgânico. Posteriormente, o material formado é tratado termicamente à temperatura de $500{ }^{\circ} \mathrm{C}$, para remoção do polímero orgânico. Adicionalmente, a temperatura é elevada até $1.000{ }^{\circ} \mathrm{C}$ para a sinterização das micropartículas e aumento da resistência mecânica $^{[30]}$.

\subsubsection{O processo de agregação de gotículas dispersas}

O processo de agregação de gotículas (gotas) dispersas inclui o método de secagem por nebulização (spray drying) e o método de emulsão. $\mathrm{O}$ spray drying consiste na dispersão de uma suspensão coloidal de sílica através de um bocal, formando pequenas gotículas do líquido (Figura 7). A pulverização da suspensão ocorre dentro de um forno com temperatura em torno de $400{ }^{\circ} \mathrm{C}$. Essa etapa resulta na evaporação da água das gotículas, empregando-se um gás de secagem quente, e na policondensação simultânea dentro das gotículas. As partículas obtidas após esse processo podem ser submetidas a um tratamento hidrotérmico para ajuste de porosidade. Tipicamente, a maioria das partículas sintetizadas por esse procedimento é esférica, contudo a morfologia depende das condições experimentais ajustadas. O tamanho das partículas produzidas varia de acordo com a concentração dos reagentes, temperatura do forno de secagem, abertura do bocal de pulverização, tamanho das gotículas e outros parâmetros. Os materiais obtidos por essa metodologia geralmente apresentam grande faixa de distribuição de partículas e necessitam de classificação (elutriação, sedimentação em líquido ou fluxo de ar) para obterem-se faixas estreitas de diâmetro de partícula para uso em $\mathrm{LC}^{[5,30]}$.

Partículas esféricas porosas também podem ser obtidas através do método de emulsão de uma suspensão coloidal, organossilano ou solução de silicato em solvente apolar no qual gotículas são formadas e, em seguida, solidificadas, formando as partículas esféricas que são separadas do meio reacional e submetidas a um tratamento térmico. É importante ressaltar, no entanto, que a distribuição do tamanho de partículas pode ser bastante ampla, dependendo das condições de emulsificação utilizadas para regular o tamanho das gotas ${ }^{[5,30]}$. Nesse contexto, Unger desenvolveu e patenteou uma metodologia para a síntese de partículas de sílica esférica em duas etapas. A síntese envolve a hidrólise parcial do TEOS em polietoxissilano (PES), formando um líquido viscoso que, posteriormente, é emulsificado por agitação em uma mistura etanol-água. Nesse sis-

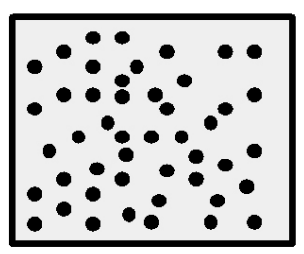

Partículas de sílica coloidal (nm)

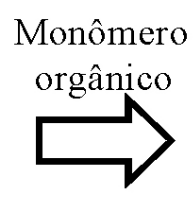

Sílica microencapsulada polímero orgânico

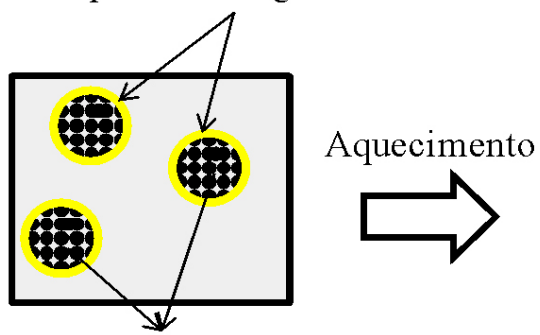

Partículas de sílica $(\mu \mathrm{m})$

Figura 6 Esquema do processo de agregação reativa. 


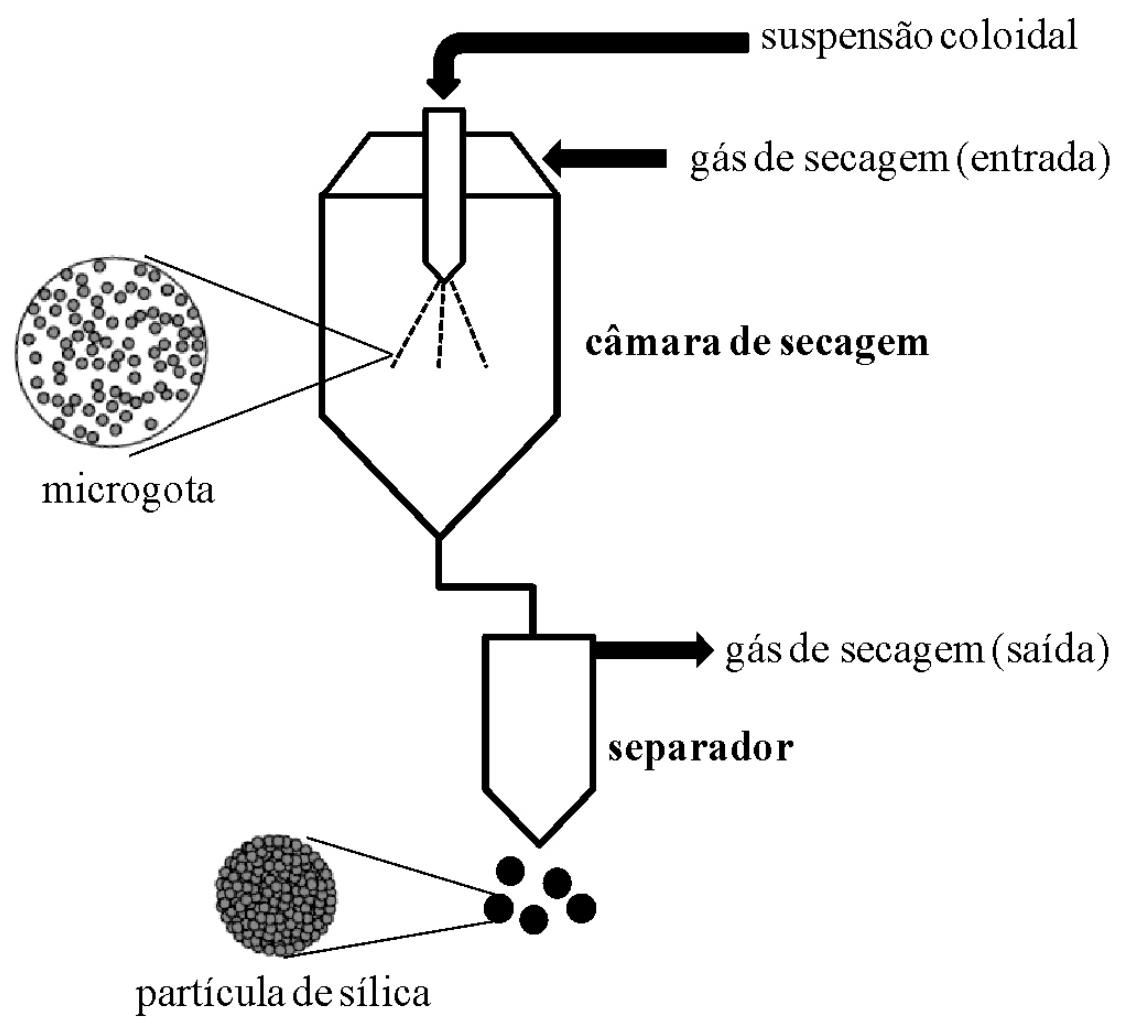

Figura 7 Representação esquemática do equipamento de spray drying.

tema reacional, esferas de PES são convertidas a sílica hidrogel através de catálise básica. As partículas esféricas de sílica são, posteriormente, convertidas para xerogel através de tratamento térmico (Figura 8) ${ }^{[33]}$.

\subsection{A sílica híbrida}

Os suportes baseados em sílica apresentam faixa de $\mathrm{pH}$ aplicável limitada (usualmente entre $\mathrm{pH} 2$ e $\mathrm{pH}$ 8) e análise em temperatura superior a $60{ }^{\circ} \mathrm{C}$, o que favorece a solubilização da sílica. Assim, outros materiais foram desenvolvidos com o objetivo de ampliar a faixa de $\mathrm{pH}$ e a temperatura nas aplicações. Dessa forma foi desenvolvido um suporte cromatográfico no qual a superfície da sílica é recoberta com uma camada de grupamentos hidreto (-Si-H), grupos formados pela reação dos silanois na superfície da sílica com o produto de hidrólise do pre-

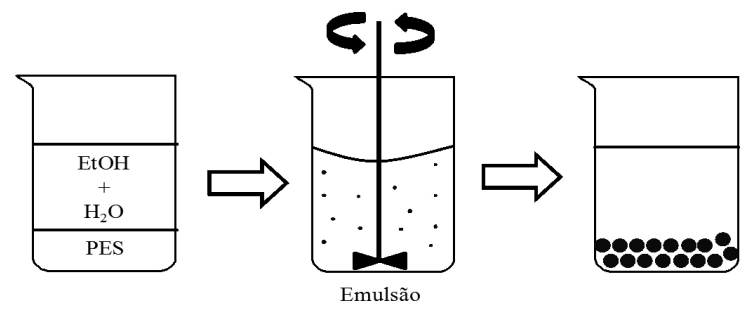

Figura 8 Processo de emulsificação no preparo de partículas de sílica.

cursor trietoxissilano (TES). Assim, os grupos polares presentes na superfície da sílica reagem, formando uma superfície apolar, e as interações indesejáveis dos analitos com os silanois residuais são minimizadas. Esses novos materiais são chamados de sílica tipo C, caracterizados por serem materiais híbridos de alta pureza e com maior estabilidade química (Figura 9a ${ }^{[34,35]}$. Nessa mesma linha, outros materiais híbridos foram desenvolvidos utilizando-se precursores que continham a ligação silício-carbono ( $\mathrm{Si}-\mathrm{C})$. 
Assim, essa ligação faz parte do suporte cromatográfico e melhora a estabilidade química dos materiais em uma faixa mais ampla de $\mathrm{pH}$. A reação de TEOS com metiltrietoxissilano leva à incorporação do grupo metil na rede polimérica da sílica (Figura 9b). Um segundo exemplo de materiais híbridos observa-se na reação de TEOS com bis(trietoxissiletano) formando suportes que contêm ligações de etano na estrutura do polímero (Figura 9c). Adicionalmente, outra<smiles>CO[Si](O)(OC)O[Si](O)(OC)O[Si](O)(OC)O[Si](O)(OC)O[Si](O)(OC)OC</smiles><smiles>CCO[SiH](C)OCC</smiles>

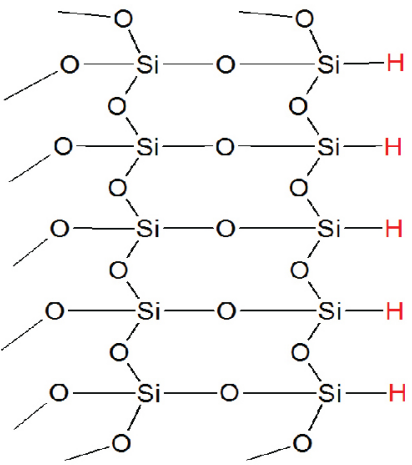

(b)<smiles>CCO[Si](C)(OCC)OCC</smiles><smiles>CO[Si]1(C)O[Si](C)(O[Si](O)(O)O[Si](C)(O)O[Si](C)(O)O[Si]2(O)O[Si](C)(OC)O[Si](OC)(OC)O2)O[Si](O)(OC)O[Si](OC)(OC)O1</smiles>

(C)<smiles>CCO[Si](CC[Si](OCC)(OCC)OCC)(OCC)OCC</smiles><smiles></smiles>

(d)<smiles>CO[Si](C)(O)O[Si](O)(OC)OC</smiles><smiles>CO[Si]([O-])(O)O[Si](O)(OC)O[Si](O)(OC)O[Si](O)(OC)OC</smiles><smiles>[R][Si](OCC)(OCC)OCC</smiles>
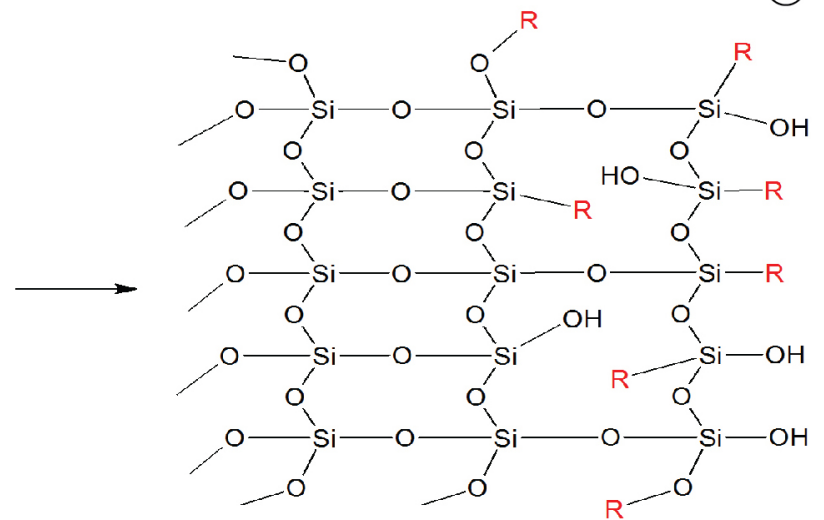

Figura 9 Representação do preparo de sílica híbrida: (a) com grupamento hidreto na superfície; (b) com ligações silício-metil; (c) com ligações de etano; e (d) com um organossilano na superfície. 
metodologia utiliza a modificação da superfície da partícula de sílica com um organossilano para ampliar a faixa de $\mathrm{pH}$ utilizada sem perder a estabilidade mecânica do material (Figura 9d) ${ }^{[1,11,36]}$. Além disso, a inserção de um grupo organossilano [aminopropiltrietoxissilano (APTES) ou viniltrimetoxissilano (VTMES)] é interessante, pois a presença desses grupos funcionais facilita a reação química com outros grupamentos orgânicos. Esse fator torna possível o desenvolvimento de novas fases estacionárias ${ }^{[37]}$.

\section{5 Óxidos inorgânicos}

Em LC, os suportes cromatográficos também podem ser obtidos a partir de óxidos metálicos, que se destacam pela estabilidade química e térmica (Figura 10). Os materiais baseados em óxido de alumínio (alumina $-\mathrm{Al}_{2} \mathrm{O}_{3}$ ) apresentam boa estabilidade em uma faixa mais ampla de $\mathrm{pH}$ (1-13). Entretanto, esse suporte cromatográfico apresenta eficiência cromatográfica inferior aos materiais baseados em sílica e, consequentemente, esse fator contribuiu para a utilização moderada desse suporte ${ }^{[38,39]}$. Suportes cromatográficos baseados em óxido de zircônio (zircônia, $\left.\mathrm{ZrO}_{2}\right)^{[40]}$ e óxido de titânio (titânia, $\left.\mathrm{TiO}_{2}\right)^{[41,42]}$ apresentam boa estabilidade em $\mathrm{pH}$ entre 1 e $14 \mathrm{e}$ sob temperaturas de até $200^{\circ} \mathrm{C}$. A superfície desses materiais apresenta sítios ácidos de Lewis e, consequentemente, fases estacionárias baseadas nesses óxidos têm demonstrado modo misto de retenção (fase reversa e troca iônica, por exemplo). Além disso, analitos com características básicas podem interagir fortemente com esses sítios ácidos, provocando caudas cromatográficas ${ }^{[30]}$. Outros óxidos metálicos também vêm sendo explorados como suportes cromatográficos. Podem-se destacar os materiais baseados em óxido de cério (céria, $\left.\mathrm{CeO}_{2}\right)^{[43]}$ e óxido de tório (tória, $\left.\mathrm{ThO}_{2}\right)^{[44]}$ Apesar das vantagens de estabilidade química e térmica, os suportes cromatográficos baseados em óxidos metálicos apresentam como desvantagem dificuldade de síntese e de funcionalização de partículas com propriedades adequadas para LC quando comparados com materiais baseados em sílica ${ }^{[1,45,46]}$.

$\mathrm{Na}$ tentativa de conciliar as vantagens individuais desses materiais, trabalhos vêm sendo conduzidos na preparação de óxidos mistos, os quais combinam as propriedades da sílica e dos óxidos metálicos. Nesse conceito, materiais mistos como sílica-alumina, sílica-zircônia, sílica-titânia e sílica-magnésia foram sintetizados e apresentaram área superficial e diâmetro de
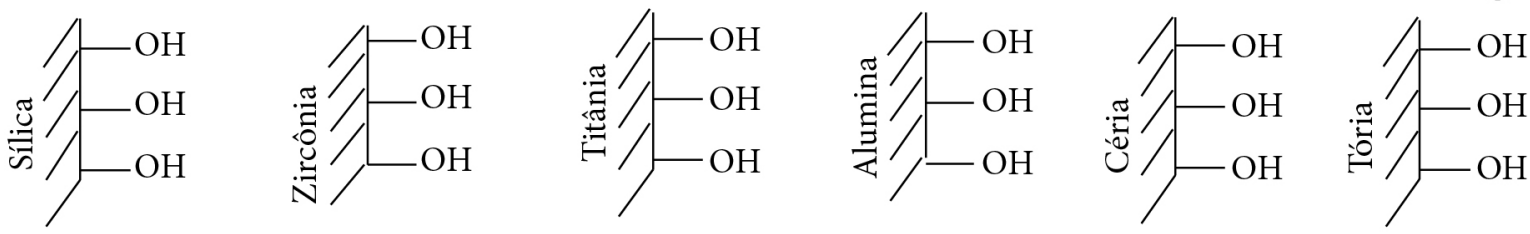

(b)
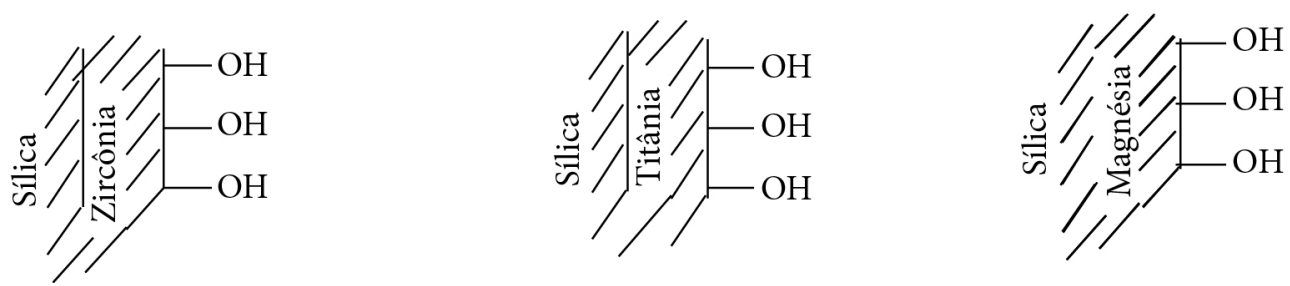

Figura 10 Suportes cromatográficos para LC: (a) óxidos inorgânicos; e (b) óxidos mistos. 
poros adequados, melhores desempenhos em temperaturas elevadas e operação em uma faixa mais ampla de $\mathrm{pH}^{[44,47,48]}$.

\subsection{Outros materiais}

Partículas esféricas porosas, baseadas em polímeros orgânicos naturais (polissacarídeos) e sintéticos também são utilizadas como suporte cromatográfico em LC ${ }^{[5]}$. Os polissacarídeos são produzidos a partir da celulose, agarose e dextran (Figura 11a). A presença de grupos hidroxila em sua estrutura possibilita posterior derivatização, alterando a seletividade do material final. Entre os polímeros orgânicos sintéticos, pode-se destacar o uso de poliestireno-divinilbenzeno (PS-DVB) em cromatografia líquida em fase reversa, troca iônica e exclusão por tamanho (Figura 11b). Outros polímeros, como metacrilatos substituídos, alcoóis polivinílicos e poliacrilamida também têm sido preparados por diferentes processos tecnológicos de fabricação. Como exemplo, pode-se citar o preparado de suporte cromatográfico baseado em poliestireno preparado pela polimerização em suspensão óleo em água, enquanto a poliacrilamida é obtida em suspensão água em óleo ${ }^{[5]}$. Assim como os polissacarídeos, a presença de grupos funcionais nas partículas permite posterior funcionalização, modificando a seletividade do material. Apesar de possuírem uma ampla faixa de $\mathrm{pH}$ aplicável, esses materiais apresentam baixa eficiência cromatográfica quando comparados com suportes cromatográficos baseados em sílica ${ }^{[49]}$. Adicionalmente, a facilidade de encolhimento e de expansão do polímero orgânico com baixo grau de ligações cruzadas (crosslinking) diminui sua resistência mecânica e, como consequência, ocorre uma limitação na pressão máxima de análise $^{[50]}$. Por outro lado, polímeros orgânicos têm se destacado como bons suportes cromatográficos em cromatografia por exclusão de tama- nho e cromatografia de troca iônica. Polímeros orgânicos têm apresentado melhor robustez em sistemas com pH elevado da fase móvel e tampões fortes quando comparados com trocadores iônicos baseados em sílica ${ }^{[51]}$.

Suportes baseados em carbono grafitado poroso (PGC) consistem em partículas esféricas de carbono totalmente porosas formadas a partir de folhas planas de átomos de carbono dispostos de forma hexagonal (Figura 11c). PGC não apresentam em sua estrutura grupos funcionais que promovam interações secundárias e são estáveis a pH entre 1-14 e, também, sob temperaturas de até $200^{\circ} \mathrm{C}$. No entanto, as partículas desse material não possuem resistência mecânica elevada e, consequentemente, apresentam uma limitação em termos de pressão máxima ${ }^{[1]}$.

\subsection{Materiais superficialmente porosos}

Além dos suportes cromatográficos totalmente porosos e dos não porosos, também são utilizados materiais superficialmente porosos. O princípio tecnológico foi utilizado na década de 1960 nos trabalhos de Horváth, no desenvolvimento de partículas de sílica peliculares $(30 \mu \mathrm{m}-50 \mu \mathrm{m})$. O suporte cromatográfico era composto por um núcleo sólido, rígido e não poroso (contas de vidro), revestido com uma película de aproximadamente $1 \mu \mathrm{m}$ de sílica porosa. A camada pelicular fina permitiu uma rápida transferência do analito na camada porosa do suporte cromatográfico e, assim, promoveu uma melhora na eficiência cromatográfica, comparada à das partículas porosas empregadas na época ${ }^{[1,7]}$. Já as partículas de sílica superficialmente porosas modernas (fused-core silica particles ou core-shell silica particles) foram desenvolvidas principalmente por Kirkland na década de 1990 e receberam destaque a partir do ano 2000. O preparo das partículas ocorre em duas etapas distintas. A primeira envolve a síntese de partículas de sílica 


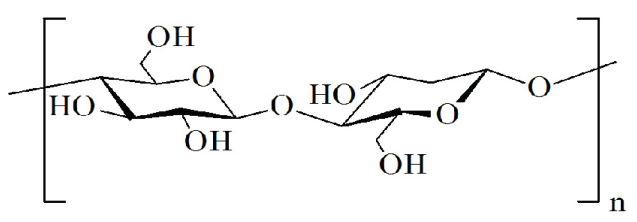

Celulose

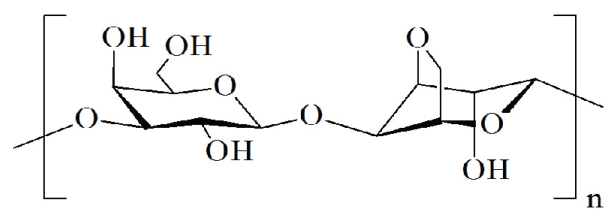

Agarose

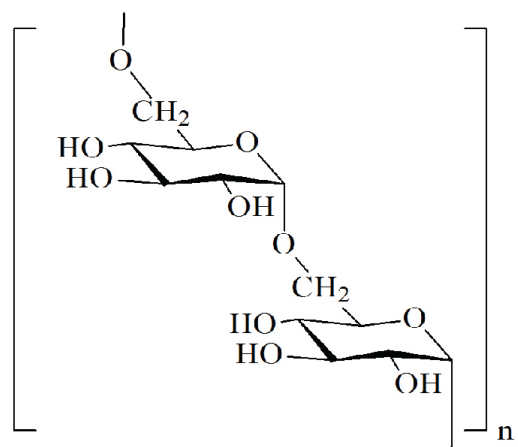

Dextran<smiles>CCC(CC(CC(CC)c1ccccc1)c1ccc([CH]CC(C)c2ccccc2)cc1)c1ccccc1</smiles>

Poliestireno-divinilbenzeno

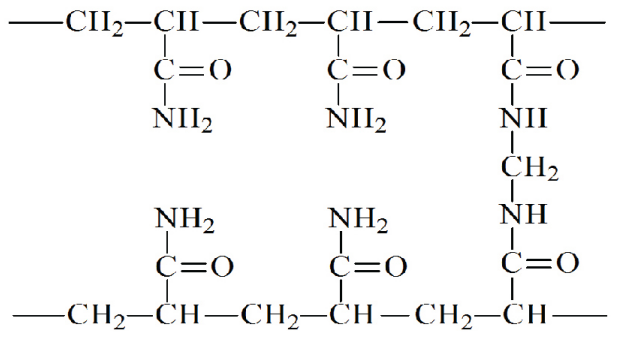

Poliacrilamida

(a) 


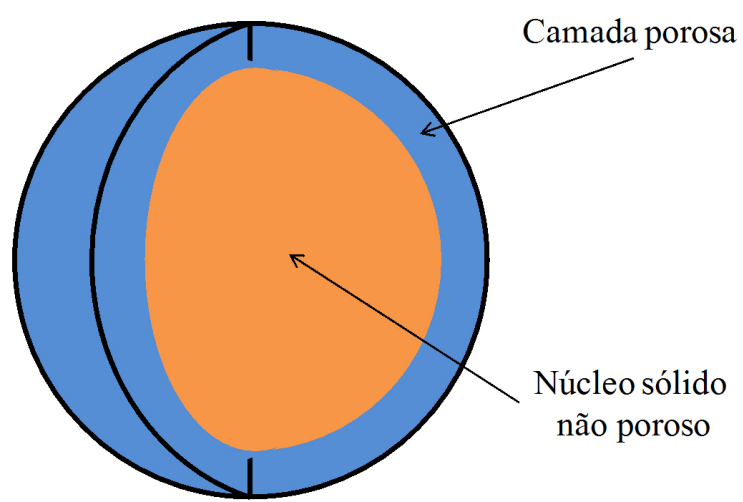

Figura 12 Partícula superficialmente porosa.

\subsection{Materiais monolíticos}

Diferentemente de materiais particulados (Figura 13a), outra possibilidade de suportes cromatográficos envolve o uso de materiais monolíticos (Figura 13b) ${ }^{[55]}$. Uma coluna monolítica possui estrutura sólida e altamente porosa que fornece alta permeabilidade da fase móvel através dos canais porosos (Figura 13b). Esses podem ser classificados como microporos, mesoporos e macroporos, dependendo do molde utilizado na síntese do monolito ${ }^{[56]}$. De acordo com a metodologia utilizada no preparo, pode-se classificá-los em de colunas monolíticas baseadas em polímeros orgânicos ${ }^{[57,58]}$ e de colunas monolíticas baseadas em polímeros inorgânicos ${ }^{[59,60]}$.

As primeiras colunas monolíticas orgânicas foram preparadas no início da década de 1990 por Svec e Fréchet. O preparo do material monolítico envolve a mistura de monômeros, agentes de ligação cruzada, solvente porogênico e catalisador radicalar que é ativado por calor ou luz UV. As colunas monolíticas inorgânicas são, em sua maioria, baseadas em sílica e obtidas pelo processo sol-gel. O primeiro trabalho bem-sucedido demonstrando a aplicação de monolito de sílica em separação cromatográfica foi realizado em 1996 por Tanaka, no qual se fez a modificação do material com o grupo C18 para atuar em cromatografia líquida em fase reversa ${ }^{[61]}$. (a)

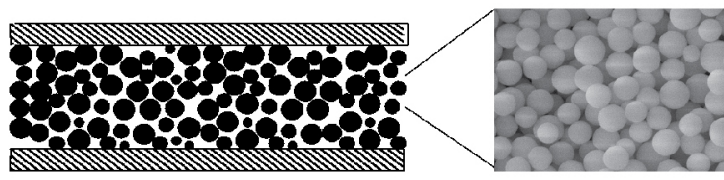

(b)

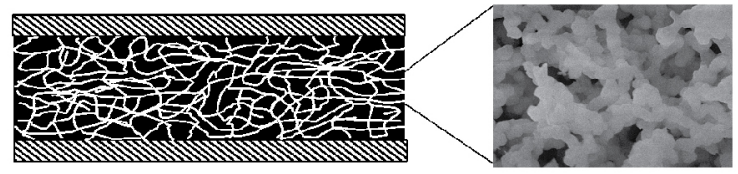

Figura 13 Característica estrutural de colunas cromatográficas: particulada (a); e monolítica (b).

A principal vantagem das colunas monolíticas em relação a colunas com preenchimento de materiais particulados é a redução do tempo de análise devido à possibilidade de utilizar vazões elevadas sem um grande aumento na pressão do sistema. As primeiras colunas monolíticas disponíveis comercialmente (2000) não apresentavam alta eficiência na separação quando comparadas com as colunas particuladas. Entretanto, recentemente (2012) foram desenvolvidas colunas monolíticas de segunda geração, chamadas de colunas monolíticas de alta resolução, as quais possuem um maior número de pratos por metro, sem comprometer a vantagem do fluxo elevado e de pressões compatíveis com os sistemas convencionais de $\mathrm{LC}^{[62]}$.

\subsection{Polímeros molecularmente impressos}

Uma abordagem de preparo de suporte cromatográfico seletivo é o uso de polímeros molecularmente impressos (MIP), fundamentada no reconhecimento molecular. Esses materiais têm se destacado pela vantagem de serem seletivos para um composto ou uma classe de compostos $^{[33-65]}$. Na primeira etapa da síntese, há uma interação das moléculas precursoras do polímero com a molécula alvo (molde - template), formando um complexo monômero-template. Essa 
interação leva a posições específicas das extremidades dos monômeros ao redor do template. A próxima etapa é a reação de polimerização, na qual ocorre a formação do polímero ao redor do template. Nesta etapa ocorre a fixação dos grupamentos dos monômeros no material polimérico. Por fim, após a remoção do template, tem-se o MIP com cavidades e sítios seletivos para a interação do template ou de estruturas análogas a ele (Figura 14) ${ }^{[66]}$. Os suportes cromatográficos baseados em MIP podem ser particulados (irregulares ou esféricos) ou monolíticos empregando precursores orgânicos, inorgânicos ou híbridos através de interações não covalentes ${ }^{[37,61,66-68]}$.

\section{Fases estacionárias}

A fase estacionária determina a retenção e a seletividade dos analitos na análise cromatográfica. Os grupos silanois na superfície da sílica apresentam polaridade e suas ligações de hidro- gênio têm a capacidade de interagir com diversas moléculas, tornando possível a separação de substâncias.

Devido às primeiras separações cromatográficas terem sido realizadas utilizando-se a sílica (que possui superfície polar) como suporte cromatográfico, esta modalidade de cromatografia líquida foi denominada fase normal, sendo caracterizada por apresentar fase estacionária mais polar em relação à fase móvel; quando a fase estacionária for menos polar do que a fase móvel é denominada de cromatografia líquida em fase reversa ${ }^{[69]}$. Adicionalmente, tem-se a cromatografia por exclusão de tamanho, cromatografia de troca iônica, cromatografia por par iônico e cromatografia por interação hidrofílica.

Em HPLC, as fases estacionárias podem ser classificadas em sorvidas, imobilizadas ou quimicamente ligadas. A primeira caracteriza-se por ser um líquido de baixa massa molar apenas sorvido na superfície do suporte cromatográfico, porém essas fases estacionárias são difíceis de serem mantidas quando submetidas às pressões

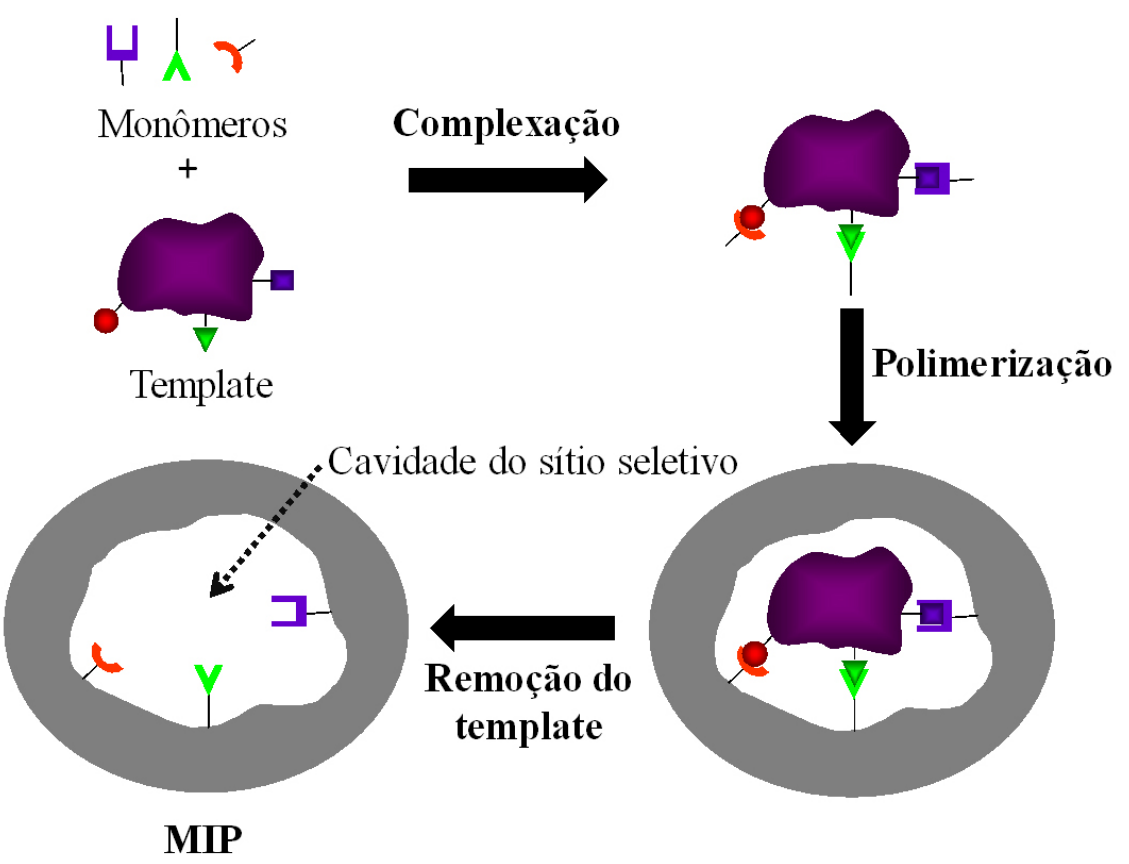

Figura 14 Ilustração esquemática de preparo do MIP. 
utilizadas na HPLC. Assim, é necessário empregar fases móveis saturadas com a fase estacionária e fazer um controle de temperatura e vazão para diminuir a remoção da fase estacionária e garantir um resultado confiável nas análises ${ }^{[70]}$.

Outra metodologia utilizada para modificar a superfície de um suporte cromatográfico é o recobrimento com polímeros orgânicos ${ }^{[9]}$. Primeiramente, o polímero é sorvido no suporte cromatográfico e, posteriormente, imobilizado por reações de entrecruzamento catalisadas por agente químico ${ }^{[71]}$ ou por processos físicos ${ }^{[72]}$ (radiação térmica, gama ou micro-ondas). Essa técnica tem a vantagem de preparar fases estacionárias estáveis, além de isolar os sítios ativos residuais dos suportes cromatográficos. Entre os polímeros utilizados como fases estacionárias destacam-se polietileno, poliestireno e polissiloxanos. A maior dificuldade nessa técnica é a obtenção de um filme fino e homogêneo ${ }^{[73]}$.

A grande concentração de grupos silanois na superfície da sílica possibilita a sua modificação química, obtendo-se as chamadas fases estacionárias quimicamente ligadas (FEQL), que possuem propriedades específicas relacionadas aos grupos ligados na superfície da sílica (Figura 15). A síntese dessas fases teve início na década de 1960, através da reação de esterificação dos grupos silanois com álcool alifático de cadeia longa (Figura 15a). Contudo, a ligação Si-O-C é relativamente fraca em soluções aquosas, sendo hidrolisada rapidamente, regenerando os grupos silanois na sílica ${ }^{[2,7,44]}$.

Na tentativa de obter FEQL estáveis foram preparados materiais a partir da reação da sílica com cloreto de tionila $\left(\mathrm{SOCl}_{2}\right)$ e, posteriormente, com reagente de Grignard, gerando ligações $\mathrm{Si}-\mathrm{C}$, ou com aminas gerando as ligações Si-N (Figura 15b). Apesar de serem ligações mais estáveis, comparadas com a ligação
Si-O-C, a ligação Si-N ainda apresenta faixa de $\mathrm{pH}$ restrita ( 4 a 8 ) e as fases obtidas por Grignard apresentam interferentes provenientes da rota sintética. A metodologia mais empregada atualmente no preparo de FEQL é a da reação de organossilanização que utiliza modificadores do tipo cloro $(\mathrm{Cl})$ ou alcoxissilano, podendo ser mono, di ou trifuncional (Figuras $15 \mathrm{c}$ e $15 \mathrm{~d})^{[7]}$. Adicionalmente, tem-se também a sílica tipo $C$, na qual um grupamento alquílico pode ser ligado quimicamente na superfície do suporte cromatográfico, através da reação dos grupamentos hidretos (Si-H), com grupamentos alquílicos terminalmente insaturados, em presença de um catalisador (Figura 15e).

Quando um reagente funcionalizante silano monofuncional [clorodimetiloctadecilssilano (ODS) por exemplo] reage com o grupo silanol na superfície da sílica, ocorre a formação da fase estacionária C18 monomérica (Figura 16). Fases obtidas por esse procedimento são reprodutíveis e apresentam boa eficiência cromatográfica devido à rápida difusão do analito na camada da fase monomérica. Entretanto, as fases monoméricas apresentam grande quantidade de silanol residual após o processo de funcionalização. Esses grupos silanois podem promover interações secundárias com os analitos e provocar alargamento do pico cromatográfico. Além disso, o uso dessa fase em $\mathrm{pH}$ baixo leva a hidrólise do grupo funcionalizador e, consequentemente, a perda de seletividade da coluna cromatográfica. Uma maneira de minimizar esses efeitos é promover uma segunda etapa de funcionalização com um reagente silano de volume menor [trimetilclorossilano (TMS)]. Esse procedimento, denominado capeamento (endcapping), diminui $20 \%$ a $30 \%$ dos silanois residuais nas partículas de sílica. 
Assim, é importante ressaltar que a interação silanol-analito é minimizada e não completamente eliminada ${ }^{[1]}$.

Outra estratégia para bloquear os grupos silanois da sílica é utilizar reagentes funcionalizantes com proteção estérica. Esses precursores são uma variação das fases monoméricas, pois os grupos metila ligados ao átomo de silício são substituídos por grupos volumosos (i-propil ou i-butil). Esses grupamentos dificultam o processo de hidrólise das fases estacionárias e, por- tanto, são mais apropriados para análise em $\mathrm{pH}$ baixo. Entretanto, as fases com proteção estérica possuem menor concentração dos ligantes na superfície do suporte cromatográfico e, consequentemente, apresentam menor retenção quando comparadas com fases estacionárias monoméricas contendo o grupamento dimetil. Fases estacionárias bidentadas apresentam maior estabilidade em meio básico e, portanto, são utilizadas em aplicações nas quais é necessário $\mathrm{pH}$ acima de 8 .
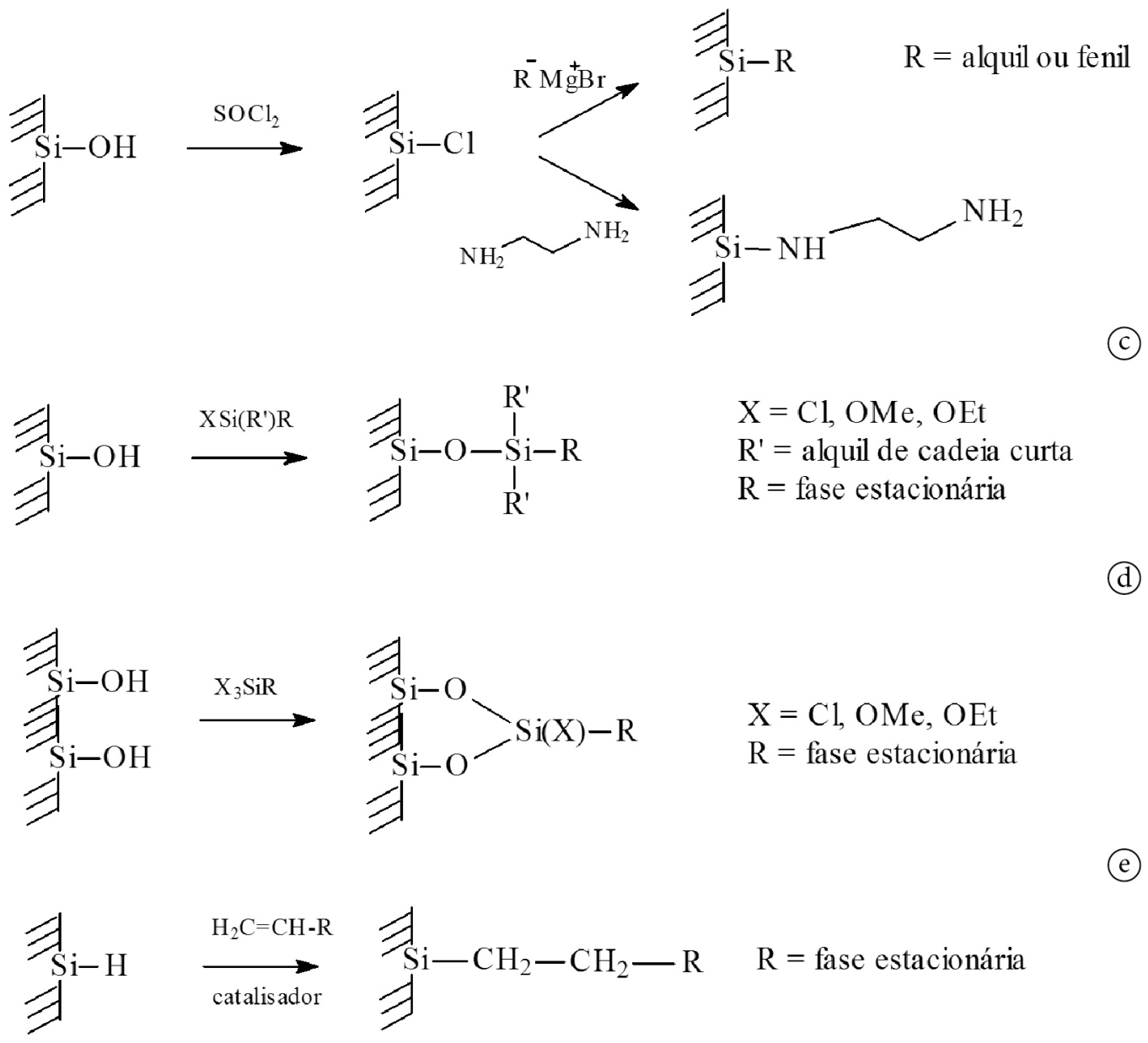

Figura 15 Obtenção de fase estacionária quimicamente ligada: (a) reação de esterificação; (b) reação com $\mathrm{SOCl}_{2}$; (c) reação de organossilanização com reagente monofuncional; (d) reação de organossilanização com reagente difuncional; e (e) reação do hidreto com grupo alquílico. 


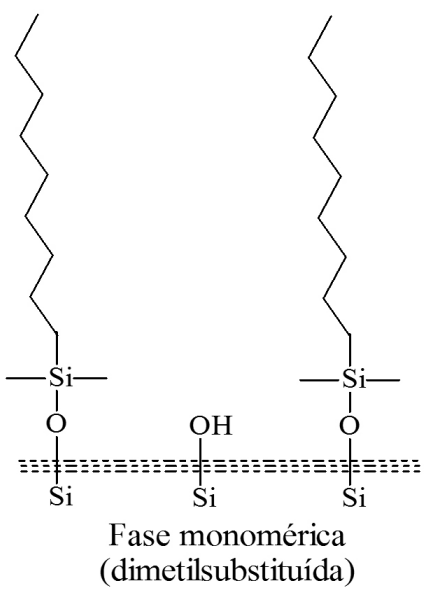

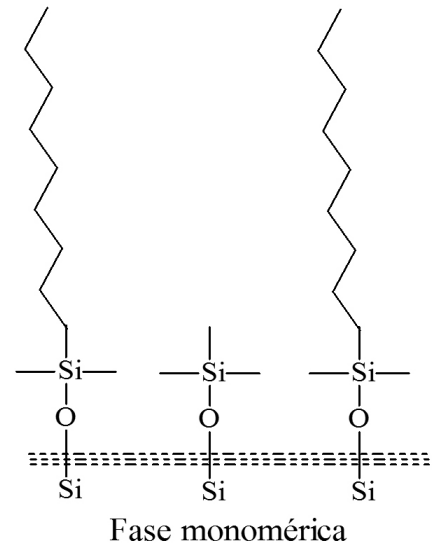

(dimetilsubstituída e com endcapping)
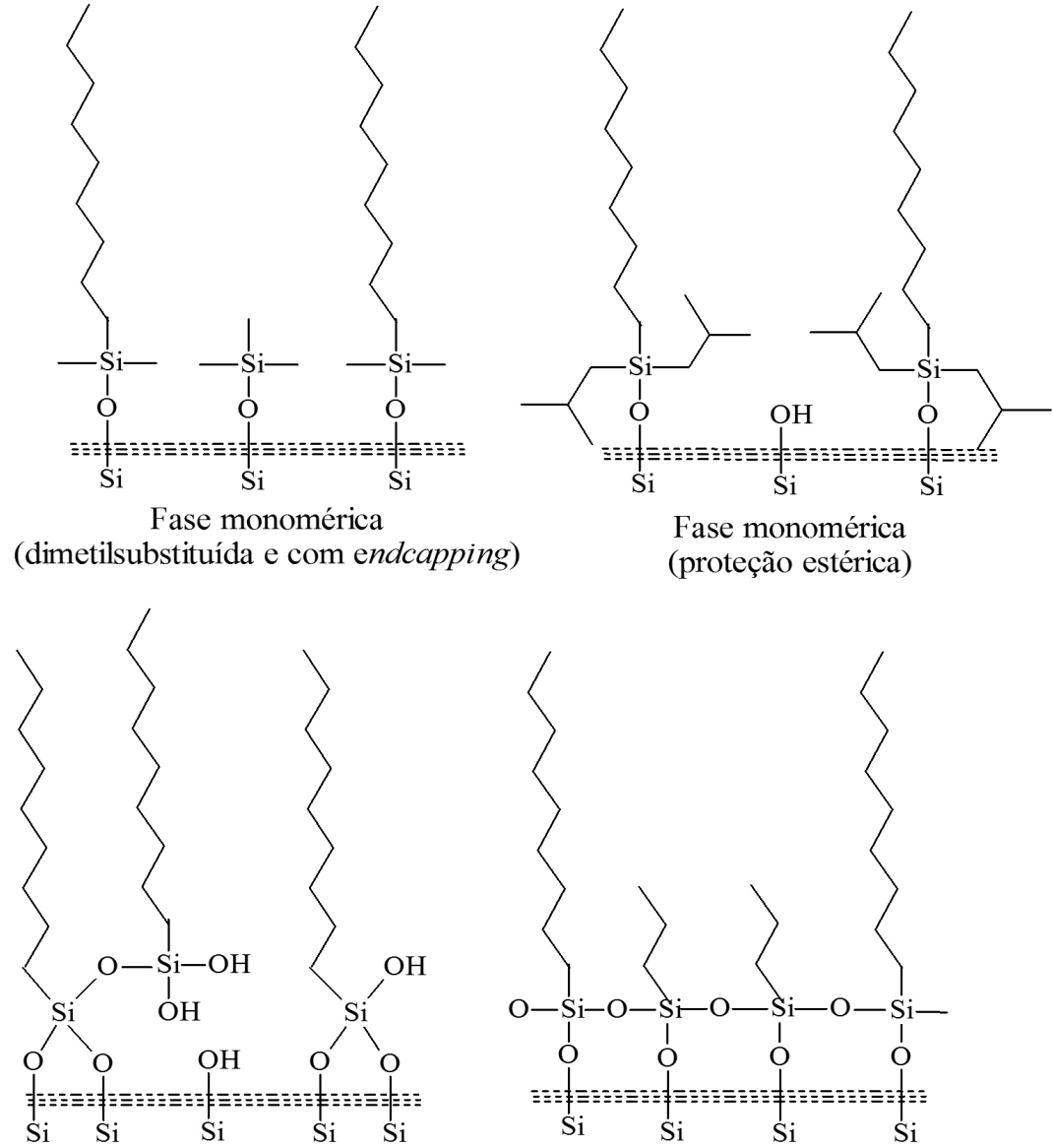

Fase polimérica (polimerização vertical)

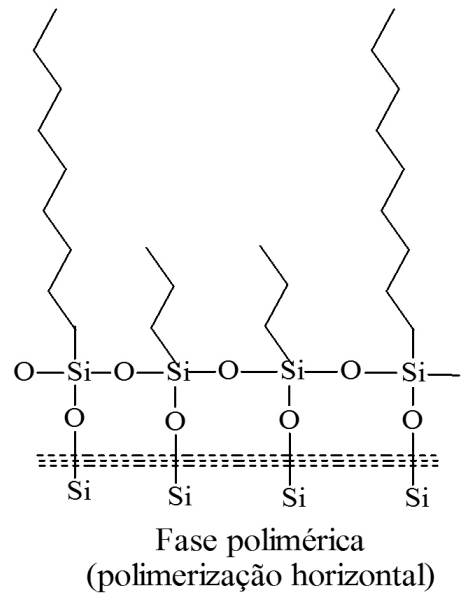

Figura 16 Estratégias para modificação da superfície da sílica.

Se um reagente silano bi ou trifuncional é empregado, dependendo das condições utilizadas, podem-se obter fases estacionárias com polimerização vertical ou horizontal. Essas fases tendem a ser mais estáveis do que as fases monoméricas em $\mathrm{pH}$ baixo e alto. Entretanto, esses materiais possuem menor reprodutibilidade de retenção e seletividade, devido à dificuldade de controlar o processo de polimerização do organossilano. Adicionalmente, as colunas contendo as fases poliméricas possuem uma menor eficiência na separação, principalmente quando vazão elevada é empregada ${ }^{[1]}$.
Atualmente, diversas fases estacionárias foram preparadas para HPLC (Figura 17) atuando no modo normal (diol, ciano, amino, $\mathrm{SiO}_{2}$ ), reverso (C30, C18, C8, C4, fenil, cicloexil, fluoradas, grupos polares embutidos) e iônico (SAX, SCX, WAX, WCX). Adicionalmente pode-se destacar a possibilidade de sintetizar fases suportadas na superfície da sílica com seletividade diferenciada. Como exemplo prático, pode-se citar o preparo de fases estacionárias contendo líquidos iônicos (ILs). Uma das principais vantagens da superfície imobilizada com fases estacionárias contendo IL é a possibilidade de alterar os cátions, ânions e a cadeia alquílica do líquido iônico. Essa vantagem fornece a capaci- 


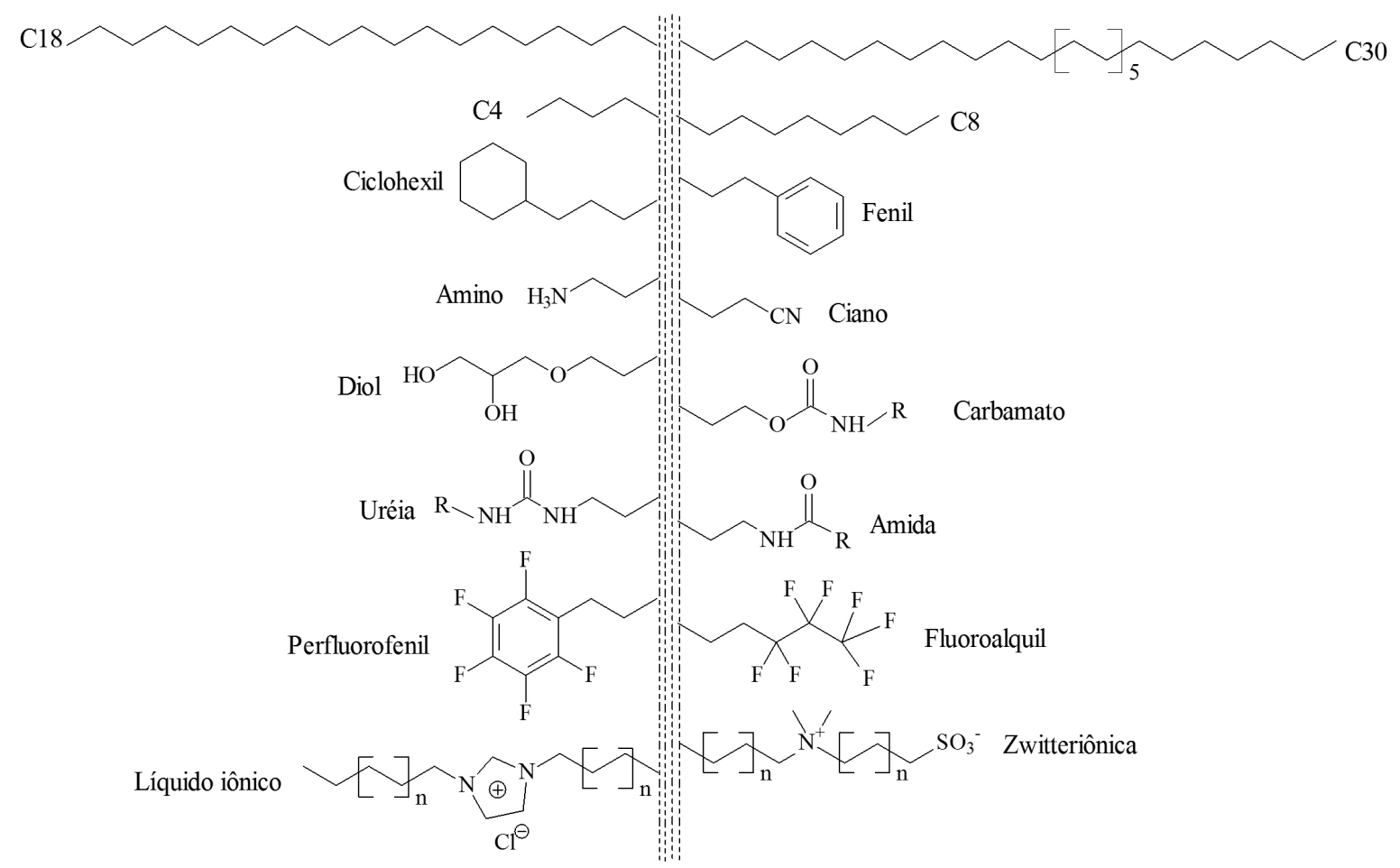

Figura 17 Representação de fases estacionárias utilizadas em HPLC.

dade de manipular a estrutura de IL na sílica e, consequentemente, as propriedades da fase estacionária $^{[10]}$. Outro exemplo é a síntese de fases zwiteriônicas, as quais possuem grupos com carga positiva e negativa que permitem mudar a seletividade da separação cromatográfica. Além disso, fases estacionárias seletivas, tais como quirais, bioafinidade, MIP, meio de acesso restrito (RAM), ampliam a aplicabilidade da HPLC e têm recebido grande atenção da comunidade científica $^{[2,3]}$.

\section{Perspectivas futuras no desenvolvimento de suportes cromatográficos}

Desde o surgimento da técnica de separação denominada HPLC, os suportes cromatográficos utilizados no preparo de fases estacionárias vêm evoluindo. Na década de 1950, as partículas para LC eram baseados em materiais poro- sos $(100 \mu \mathrm{m}-200 \mu \mathrm{m}$ de diâmetro $)$ e com formato irregular. Já na década de 1960 surgiram as partículas de sílica peliculares $(30 \mu \mathrm{m}-50 \mu \mathrm{m})$. A transição de partículas peliculares para partículas porosas com diâmetro menor iniciou-se na década de 1970. Nesse período foram sintetizadas micropartículas de sílica irregular e porosa com diâmetro médio de $10 \mu \mathrm{m}$. Com o passar do tempo e o melhor entendimento/ aperfeiçoamento dos métodos de síntese, partículas esféricas porosas foram desenvolvidas com sucesso. Posteriormente surgiram as partículas esféricas porosas de $5 \mu \mathrm{m}$ (decênio 1980), 3,5 $\mu \mathrm{m}$ e 3,0 $\mu \mathrm{m}$ (decênio 1990) e sub-2,0 $\mu \mathrm{m}$ (decênio 2000). Nesse período (anos 1990), partículas não porosas de 1,5 $\mu \mathrm{m}$ também estavam disponíveis comercialmente; na década seguinte surgiram as partículas superficialmente porosas (sub$2,0 \mu \mathrm{m})$ e as colunas monolíticas. Atualmente, uma grande variedade de suportes cromatográficos está disponível comercialmente para HPLC. 
Tabela 1 Diminuição do tamanho das partículas em LC e sua influência na eficiência da coluna (N).

\begin{tabular}{|c|c|c|c|}
\hline Ano & Tamanho da partícula & Morfologia & $\mathrm{N} / 15 \mathrm{~cm}$ \\
\hline Anos 1950 & $100 \mu \mathrm{m}-200 \mu \mathrm{m}$ & Irregular porosa & 200 \\
\hline 1967 & $50 \mu \mathrm{m}$ & Pelicular esférica & 1.000 \\
\hline Anos 1970 & $10 \mu \mathrm{m}$ & $\begin{array}{l}\text { Irregular porosa } \\
\text { Esférica porosa }\end{array}$ & 6.000 \\
\hline 1985 & $5 \mu \mathrm{m}$ & Esférica porosa & 12.000 \\
\hline 1992 & $3 \mu \mathrm{m}$ e $3,5 \mu \mathrm{m}$ & Esférica porosa & 22.000 \\
\hline 1996 & $1,5 \mu \mathrm{m}$ & Esférica não porosa & 30.000 \\
\hline 2000 & - & Monolítica & 15.000 \\
\hline 2000 & $2,5 \mu \mathrm{m}$ & Esférica porosa & 25.000 \\
\hline 2004 & $1,7 \mu \mathrm{m}$ & Esférica porosa & 35.000 \\
\hline 2007 & 1,6 e $2,6 \mu \mathrm{m}$ & Superficialmente porosa & 30.000 \\
\hline 2012 & - & Monolítica de segunda geração & 22.500 \\
\hline
\end{tabular}

Cada material possui suas vantagens e desvantagens, consequentemente, o conhecimento de cada suporte cromatográfico é fundamental para o sucesso da separação na aplicação escolhida. De forma resumida, a Tabela 1 apresenta a evolução dos suportes cromatográficos, a redução no tamanho das partículas e o aumento na eficiência das colunas.

A tendência tecnológica na área de separação é a diminuição do tamanho da partícula e também do diâmetro interno das colunas cromatográficas (capilar e nano-LC) ${ }^{[74-79]}$. Se o foco do trabalho for análise rápida, colunas menores que $100 \mathrm{~mm}$ de comprimento podem ser utilizadas com essas partículas, sem gerar pressões exageradamente elevadas para os padrões atuais. Por outro lado, se o objetivo da análise é aumentar a eficiência e resolução de um método, colunas com tamanho tradicional ( $\mathrm{L}=150 \mathrm{~mm}-300 \mathrm{~mm}$ ) empacotadas com as partículas pequenas têm demonstrado ser uma boa opção, apesar da limitação instrumental, devido à pressão elevada.

Nesse contexto, diversos trabalhos na literatura têm demonstrado resultados interessantes. Jorgenson et al. ${ }^{[80,81]}$ realizaram uma sepa- ração empregando uma coluna com dimensões $430 \mathrm{~mm} \times 30 \mu \mathrm{m} \times 1,0 \mu \mathrm{m}$ e C18 não poroso. $\mathrm{A}$ pressão do sistema foi de 7.000 bar (103.000 psi) e o tempo de análise foi inferior a quatro minutos, com um número de pratos de aproximadamente 300.000, considerado elevado para HPLC, de acordo com os padrões atuais. Lee et al. ${ }^{[82]}$ utilizaram uma coluna capilar contendo partículas C18 não porosas $(150 \mathrm{~mm} \times 50 \mu \mathrm{m} \times 1,0$ $\mu \mathrm{m})$, temperatura de $80{ }^{\circ} \mathrm{C}$ e pressão de 2.413 bar e obtiveram tempo de análise de 36 segundos. Mellors e Jorgenson ${ }^{[83]}$ realizaram a comparação de colunas, uma contendo partículas de sílica não porosa de $1 \mu \mathrm{m}$ com uma contendo partículas de sílica híbrida porosa de 1,5 $\mu \mathrm{m}$. Foi observado que ambas as colunas apresentaram resultados similares para eficiência da coluna e resistência mecânica em pressão de 4500 bar. Cintron e Colon ${ }^{[84]}$ realizaram a síntese de partículas não porosas de sílica, com diâmetro médio de 0,67 $\mu \mathrm{m}$, e, após a funcionalização com C18, prepararam uma coluna de $90 \mathrm{~mm} \times 50 \mu \mathrm{m}$, contendo as partículas sub-1 $\mu \mathrm{m}$. Empregando um sistema de cromatografia líquida de ultra eficiência (UHPLC) capaz de trabalhar em 3.500 bar 
(50.000 psi), foi possível promover a separação cromatográfica em 3,2 minutos, com uma eficiência de 500.000 pratos por metro. Apesar da alta pressão utilizada, a velocidade linear empregada na análise $\left(1,3 \mathrm{~mm} \mathrm{~s}^{-1}\right)$ foi inferior à velocidade linear ótima para a coluna $\left(3,0 \mathrm{~mm} \mathrm{~s}^{-1}\right)$.

A principal limitação para o uso de colunas capilares e nano com partículas altamente eficientes está relacionada com a não disponibilidade de equipamentos comerciais adequados para trabalhar nessas condições. Atualmente, os sistemas suportam pressões máximas ao redor de 1.000 a 1.350 bar. Uma vez superada essa problemática, as possibilidades de uma marcante evolução nas diversas áreas de aplicação (ambiental, biológica, farmacêutica, proteômica, metabolômica, genômica) poderão, finalmente, serem alcançadas.

\section{Conclusão}

Pesquisas relacionadas com o desenvolvimento de suportes cromatográficos e fases estacionárias mais estáveis (quimica e mecanicamente) e com seletividade diferenciada devem continuar em destaque com a finalidade de aprimorar o desempenho cromatográfico em diversas áreas de aplicação. Nesse contexto, novas fases estacionárias baseadas em sílica deverão ser desenvolvidas, devido às vantagens da sílica em relação aos outros materiais. Adicionalmente, a complexidade e simplicidade serão as diretrizes no desenvolvimento tecnológico de novos materiais para HPLC. Por um lado, as novidades geralmente são relacionadas com estruturas e processos sintéticos complexos. Por outro lado, a simplicidade torna o processo mais facilmente acessível e economicamente viável, o que é muito importante para a sua industrialização.
Futuramente, a evolução dos sistemas miniaturizados (capilar e nano-LC) permitirá seu uso rotineiro nos laboratórios com partículas pequenas (sub-2 $\mu \mathrm{m})$, gerando uma eficiência cromatográfica elevada, com um tempo de análise curto, sem a limitação de pressão existente atualmente (1.350 bar). Por fim, deve-se considerar que a próxima etapa de evolução das colunas de HPLC seja a consolidação de colunas tubulares abertas em LC (OT-LC), similarmente ao grande sucesso que alcançaram em GC. Dessa forma, a cromatografia caminha para a vertente de junção dos modos de separação (cromatografia líquida, fluido supercrítico e a gás) no desenvolvimento da cromatografia unificada ${ }^{[85,86]}$.

\section{Referências}

1 Snyder LR, Kirkland JJ, Dolan JW. Introduction to modern liquid chromatography. Hoboken: Wiley; 2010. p. 1-17.

2 Neue UD. in HPLC columns: theory, technology, and practice. New York: Wiley-VCH; 1997. p. 1-17.

3 Braithwaite A, Smith FJ. Chromatographic methods. London: Blackie Academic \& Professional; 1996. p. 1-10.

4 Snyder SR, Kirkiland JJ, Glajch JL. Practical HPLC method development. New York: Wiley; 1997. p. 1-15. http://dx.doi.org/10.1002/9781118592014

5 Arshady R. Beaded polymer supports and gels: I. Manufacturing techniques. Journal of Chromatography A 1991; 586(2):181-197. http:// dx.doi.org/10.1016/0021-9673(91)85124-X

6 Berthod A. Silica: backbone material of liquid chromatographic column packings. Journal of Chromatography A 1991; 549:1-28. http://dx.doi. org/10.1016/S0021-9673(00)91415-8

7 Scott RPW. Silica gel and bonded phases: their production, properties and use in LC. Chichester: Wiley; 1993. p. 1-6.

8 Prado AGS, Faria EA, Padilha PM. Aplicação e modificação química da sílica gel obtida de areia. Quimica Nova 2005; 28(3):544-547. http://dx.doi. org/10.1590/S0100-40422005000300030 
9 Petro M, Berek D. Polymers immobilized on silica gels as stationary phases for liquid chromatography. Chromatographia 1993; 37(9-10):549-561. http:// dx.doi.org/10.1007/BF02275796

10 Qiu H, Liang X, Sun M, Jiang S. Development of silica-based stationary phases for high-performance liquid chromatography. Analytical and Bioanalytical Chemistry 2011; 399(10):3307-3322. PMid:21221544. http://dx.doi.org/10.1007/s00216-010-4611-x

11 Maldaner L, Collins CH, Jardim ICSF. Fases estacionárias modernas para cromatografia líquida de alta eficiência em fase reversa. Quimica Nova 2010; 33(7):1559-1568. http://dx.doi.org/10.1590/S010040422010000700024

12 Ikegami T, Tomomatsu K, Takubo H, Horie K, Tanaka N. Separation efficiencies in hydrophilic interaction chromatography. Journal of Chromatography A 2008; 1184(1-2):474-503. PMid:18294645. http://dx.doi. org/10.1016/j.chroma.2008.01.075

13 Buszewski B, Jezierska M, Wełniak M, Berek D. Survey and Trends in the Preparation of Chemically Bonded Silica Phases for Liquid Chromatographic Analysis. Journal of High Resolution Chromatography 1998; 21(5):267-281. http://dx.doi.org/10.1002/(SICI)15214168(19980501)21:5<267::AID-JHRC267>3.0.CO;2-7

14 Buszewski B, Kowalska S, Krupczynska K. New Generation of Chromatographic Packings and Columns for Determination of Biologically Active Compounds. Critical Reviews in Analytical Chemistry 2005; 35(2):89-116. http://dx.doi. org/10.1080/10408340500207367

15 Hiratsuka RS, Santilli CV, Pulcinelli SH. Quimica Nova 1995; 18(2):171-180. Quimica Nova 1995; 18(2):171180.

16 Unger KK. Porous silica: its properties and use as support in column liquid chromatography. Amsterdam: Elsevier; 1979. p. 1-9.

17 Iler RK. The chemistry of silica: solubility, polymerization, colloid and surface properties, and biochemistry. New York: Wiley; 1979. p. 1-6.

18 Rao AV, Rao AP, Kulkarni MM. Comparative studies on the surface chemical modification of silica aerogels based on various organosilane compounds of the type $\mathrm{R}_{\mathrm{n}} \mathrm{SiX}_{4-\mathrm{n}}$. Journal of Non-Crystalline Solids 2004; 350:224-229. http://dx.doi.org/10.1016/j. jnoncrysol.2004.06.034

19 Barrett DA, Brown VA, Watson RC, Davies MC, Shaw PN, Ritchie HJ, et al. Effects of acid treatment on the trace metal content of chromatographic silica: bulk analysis, surface analysis and chromatographic performance of bonded phases. Journal of Chromatography A 2001; 905(1-2):69-83. http:// dx.doi.org/10.1016/S0021-9673(00)01000-1

20 Lee SG, Jang YS, Park SS, Kang BS, Moon BY, Park HC. Synthesis of fine sodium-free silica powder from sodium silicate using $w / o$ emulsion. Materials Chemistry and Physics 2006; 100(2-3):503-506. http:// dx.doi.org/10.1016/j.matchemphys.2006.02.001

21 Park M, Menon VC, Komarneni S. Ethanol Washing Effect on Textural Properties of the Sodium SilicateDerived Silica Xerogel. Journal of Sol-Gel Science and Technology 1998; 12(1):15-20. http://dx.doi. org/10.1023/A:1008648925228

22 Le VH, Thuc CNH, Thuc HH. Synthesis of silica nanoparticles from Vietnamese rice husk by sol-gel method. Nanoscale Research Letters 2013; 58(8):1-10. http://dx.doi.org/10.1186/1556-276X-8-58

23 Essien ER, Olaniy OA, Adams LA, Shaibu RO. Sol-gel-derived porous silica: economic synthesis and characterization. Journal of Minerals and Materials Characterization and Engineering 2012; 11:976-981.

24 Stöber W, Fink A, Bohn E. Controlled growth of monodisperse silica spheres in the micron size range. Journal of Colloid and Interface Science 1968; 26(1):6269. http://dx.doi.org/10.1016/0021-9797(68)90272-5

25 Chang SM, Lee M, Kim WS. Preparation of large monodispersed spherical silica particles using seed particle growth. Journal of Colloid and Interface Science 2005; 286(2):536-542. PMid:15897068. http:// dx.doi.org/10.1016/j.jcis.2005.01.059

26 Chou KS, Chen CC. The critical conditions for secondary nucleation of silica colloids in a batch Stöber growth process. Ceramics International 2008; 34(7):1623-1627. http://dx.doi.org/10.1016/j. ceramint.2007.07.009

27 Unger KK, Kumar D, Grün M, Büchel G, Lüdtke S, Adam T, et al. Synthesis of spherical porous silicas in the micron and submicron size range: challenges and opportunities for miniaturized high-resolution chromatographic and electrokinetic separations. Journal of Chromatography A 2000; 892(1-2):47-55. http://dx.doi.org/10.1016/S0021-9673(00)00177-1

28 Shimura N, Ogawa M. Growth of Nanoporous Silica Spherical Particles by the Stöber Method Combined with Supramolecular Templating Approach. Bulletin 
of the Chemical Society of Japan 2005; 78(6):11541159. http://dx.doi.org/10.1246/bcsj.78.1154

29 Keane DA, Hanrahan JP, Copley MP, Holmes JD, Morris MA. A modified Stöber process for the production of mesoporous Sub 2 micron silica microspheres; applications in HPLC. Journal of Porous Materials 2010; 17(2):145-152. http://dx.doi. org/10.1007/s10934-009-9274-7

30 Nawrocki J, Dunlap C, McCormick A, Carr PW. Part I. Chromatography using ultra-stable metal oxide-based stationary phases for HPLC. Journal of Chromatography A 2004; 1028(1):1-30. PMid:14969280.

31 Giraldo LF, Lopez BL, Perez L, Urrego S, Sierra L, Mesa M. Mesoporous Silica Applications. Macromolecular Symposia 2007; 258:129-141. http:// dx.doi.org/10.1002/masy.200751215

32 Shiba K, Shimura N, Ogawa M. Mesoporous Silica Spherical Particles. Journal of Nanoscience and Nanotechnology 2013; 13(4):2483-2494. PMid:23763122. http://dx.doi.org/10.1166/ jnn.2013.7423

33 Hohenesche CDFV, Ehwald V, Unger KK. Development of standard operation procedures for the manufacture of $n$-octadecyl bonded silicas as packing material in certified reference columns for reversed-phase liquid chromatography. Journal of Chromatography A 2004; 1025(2):177-187. http:// dx.doi.org/10.1016/j.chroma.2003.10.091

34 Pesek JJ, Matyska MT, Dalal L. Evaluation of HydrideBased Stationary Phases for LC-MS. Chromatographia, 2005; 62(11-12):595-601. http://dx.doi.org/10.1365/ s10337-005-0661-1

35 Pesek JJ, Matyska MT. Hydride-based silica stationary phases for HPLC: Fundamental properties and applications. Journal of Separation Science 2005; 28(15):1845-1854. PMid:16276778. http://dx.doi. org/10.1002/jssc.200500201

36 Tonhi E, Collins KE, Jardim ICSF, Collins CH. Fases estacionárias para cromatografia líquida de alta eficiência em fase reversa (CLAE-FR) baseadas em superfícies de óxidos inorgânicos funcionalizados. Quimica Nova 2002; 25(4):616-623. http://dx.doi. org/10.1590/S0100-40422002000400017

37 Kickelbick G. Hybrid materials. Weinheim: Wiley-VCH; 2006. p. 498. http://dx.doi. org/10.1002/9783527610495

38 Pesek JJ, Matyska MT. Modified aluminas as chromatographic supports for high-performance liquid chromatography. Journal of Chromatography A 2002; 952(1-2):1-11. http://dx.doi.org/10.1016/S00219673(00)00176-X

39 Buchmeiser MR. New synthetic ways for the preparation of high-performance liquid chromatography supports. Journal of Chromatography A 2001; 918(2):233-266. http://dx.doi.org/10.1016/ S0021-9673(00)00129-1

40 Nawrocki J, Rigney M, McCormick A, Carr PW. Chemistry of zirconia and its use in chromatography. Journal of Chromatography A 1993; 657(2):229-282. http://dx.doi.org/10.1016/0021-9673(93)80284-F

41 Pesek J, Matyska M, Ramakrishnan J. Synthesis and characterization of titania based stationary phases using the silanization/hydrosilation method. Chromatographia 1997; 44(9):538-544. http://dx.doi. org/10.1007/BF02466748

42 Winkler J, Marmé S. Titania as a sorbent in normal-phase liquid chromatography. Journal of Chromatography A 2000; 888(1-2):51-62. http:// dx.doi.org/10.1016/S0021-9673(00)00489-1

43 Akama Y, Kanno H. Liquid Chromatographie separation of polycyclic aromatic hydrocarbons with cerium(IV) oxide as packing material. Analytica Chimica Acta 1995; 309(1):153-156. http://dx.doi. org/10.1016/0003-2670(95)00058-8

44 Stella C, Rudaz S, Veuthey J, Tchapla A. Silica and other materials as supports in liquid chromatography. Chromatographic tests and their importance for evaluating these supports. Part I. Chromatographia 2001; 53(1):S113-S131. http://dx.doi.org/10.1007/ BF02490318

45 Silva CR, Airoldi C, Collins KE, Collins CH. Preparation and characterization of a new $\mathrm{C}_{18}$ urea phase based on titanized silica. Journal of Chromatography A 2005; 1087(1-2):29-37. PMid:16130694. http://dx.doi. org/10.1016/j.chroma.2005.03.113

46 Silva CR, Airoldi C, Collins KE, Collins CH. A new generation of more $\mathrm{pH}$ stable reversed phases prepared by silanization of zirconized silica. Journal of Chromatography A 2008; 1191(1-2):9098. PMid:18243228. http://dx.doi.org/10.1016/j. chroma.2008.01.017

47 Kaneko S, Mitsuzawa T, Ohmori S, Nakamura M, Nobuhara K, Masatani M. Separation behaviour of silica-containing mixed oxides as column packing materials for liquid chromatography. Journal of 
Chromatography A 1994; 669(1-2):1-7. http://dx.doi. org/10.1016/0021-9673(94)80331-5

48 Goraieb K, Collins C. Evaluation of a Doubly Zirconized Silica-Based Stationary Phase for HPLC. Chromatographia 2013; 76(15-16):899-908. http:// dx.doi.org/10.1007/s10337-013-2499-2

49 Dawkins JV, Lloyd LL, Warner FP. Chromatographic Characteristics of polymer-based high-performance liquid chromatography packings. Journal of Chromatography A 1986; 352:157-167. http://dx.doi. org/10.1016/S0021-9673(01)83376-8

50 Lanças FM. Cromatografia líquida moderna: HPLC/ CLAE. Campinas: Atomo; 2009. p. 1-14.

51 Majors RE. Advances in the Design of HPLC Packings. Lc Gc North America 2000; 18(6):586-598.

52 Kirkland JJ, Truszkowski FA, Dilks CH Jr, Engel GS. Superficially porous silica microspheres for fast high-performance liquid chromatography of macromolecules. Journal of Chromatography A 2000; 890(1):3-13. http://dx.doi.org/10.1016/S00219673(00)00392-7

53 Kamour R, Ammar A, El-Attug M, Almog T. Development of fused-core silica HPLC columns and their recent pharmaceutical and biological applications: A review. International Journal of Pharmacy and Pharmaceutical Sciences 2013; 5(Suppl 3):926-930.

$54 \mathrm{Li}$ WH, Stover HDH. Monodisperse Cross-Linked Core-Shell Polymer Microspheres by Precipitation Polymerization. Macromolecules 2000; 33(12):43544360. http://dx.doi.org/10.1021/ma9920691

55 Svec F, Peters EC, Sýkora D, Fréchet JMJ. Design of the monolithic polymers used in capillary electrochromatography columns. Journal of Chromatography A 2000; 887(1-2):3-29. http://dx.doi. org/10.1016/S0021-9673(99)01232-7

56 Rouquerol J, Avnir D, Fairbrigde CW, Everett DH, Haynes JH, Pernicone N, et al. Recommendations for the characterization of porous solids (Technical Report). Pure and Applied Chemistry 1994; 66(8):17391758. http://dx.doi.org/10.1351/pac199466081739

57 Svec F, Frechet JM. Continuous rods of macroporous polymer as high-performance liquid chromatography separation media. Analytical Chemistry 1992; 64(7):820-822. http://dx.doi.org/10.1021/ ac00031a022

58 Sýkora D, Svec F, Fréchet JMJ. Separation of oligonucleotides on novel monolithic columns with ion-exchange functional surfaces. Journal of Chromatography A 1999; 852(1):297-304. http:// dx.doi.org/10.1016/S0021-9673(99)00004-7

59 Miyabe K, Cavazzini A, Gritti F, Kele M, Guiochon G. Moment Analysis of Mass-Transfer Kinetics in $\mathrm{C}_{18}$-Silica Monolithic Columns. Analytical Chemistry 2003; 75(24):6975-6986. PMid:14670061. http:// dx.doi.org/10.1021/ac0302206

60 Minakuchi H, Nakanishi K, Soga N, Ishizuka N, Tanaka N. Octadecylsilylated Porous Silica Rods as Separation Media for Reversed-Phase Liquid Chromatography. Analytical Chemistry 1996; 68(19):3498-3501. PMid:21619283. http://dx.doi. org/10.1021/ac960281m

61 Liu H, Row KH, Yang G. Monolithic Molecularly Imprinted Columns for Chromatographic Separation. Chromatographia 2005; 61(9-10):429-432. http:// dx.doi.org/10.1365/s10337-005-0531-x

62 Unger KK, Liapis AI. Adsorbents and columns in analytical high-performance liquid chromatography: A perspective with regard to development and understanding. Journal of Separation Science 2012; 35(10-11):1201-1212. PMid:22555863. http://dx.doi. org/10.1002/jssc. 201200042

63 Turiel E, Martín-Esteban A. Molecularly imprinted polymers for sample preparation: A review. Analytica Chimica Acta 2010; 668(2):87-99. PMid:20493285. http://dx.doi.org/10.1016/j.aca.2010.04.019

64 Xu Z, Chen S, Huang W, Fang G, Pingzhu H, Wang S. Study on an on-line molecularly imprinted solidphase extraction coupled to high-performance liquid chromatography for separation and determination of trace estrone in environment. Analytical and Bioanalytical Chemistry 2009; 393(4):1273-1279. PMid:19104786. http://dx.doi.org/10.1007/s00216008-2544-4

65 Watabe Y, Kubo T, Nishikawa T, Fujita T, Kaya K, Hosoya K. Fully automated liquid chromatographymass spectrometry determination of $17 \beta$-estradiol in river water. Journal of Chromatography A 2006; 1120(1-2):252-259. PMid:16460748. http://dx.doi. org/10.1016/j.chroma.2006.01.057

66 Figueiredo EC, Dias ACB, Arruda MAZ. Impressão molecular: uma estratégia promissora na elaboração de matrizes para a liberação controlada de fármacos. Revista Brasileira de Ciências Farmacêuticas 2008; 44(3):361-375. http://dx.doi.org/10.1590/S151693322008000300005 
67 Remcho VT, Tan Z. Molecular imprint polymers recognize specific compounds and show promise as separation media, especially for chiral molecules. Analytical Chemistry 1999; 71(7):248A-255A. PMid:21649059. http://dx.doi.org/10.1021/ac990292q

68 Haginaka J. Molecularly imprinted polymers as affinity-based separation media for sample preparation. Journal of Separation Science 2009; 32(10):1548-1565. PMid:19472278. http://dx.doi. org/10.1002/jssc.200900085

69 Collins CH, Braga GL, Bonato PS. Introdução a métodos cromatográficos. Campinas: UNICAMP; 1997. p. 1-10.

70 Ohmacht R, Kele M, Matus Z. Polymer coated stationary phases for liquid chromatography. Chromatographia 1989; 28(1):19-23. http://dx.doi. org/10.1007/BF02290376

71 Bien-Vogelsang U, Deege A, Figge H, Köhler J, Schomburg G. Syntheses of stationary phases for reversed-phase LC using silanization and polymer coating. Chromatographia, 1984; 19(1):170-179. http://dx.doi.org/10.1007/BF02687734

72 Tonhi E, Collins KE, Collins CH. High-performance liquid chromatographic stationary phases based on poly(methyloctylsiloxane) immobilized on silica: II. Chromatographic evaluation. Journal of Chromatography A 2002; 948(1-2):109-119. http:// dx.doi.org/10.1016/S0021-9673(02)00006-7

73 Hanson M, Unger KK. Polymer coatings as stationary phases in high-performance liquid chromatography. Trends Analytical Chemistry 1992; 11(10):368-373. http://dx.doi.org/10.1016/0165-9936(92)80026-3

74 Gama MR, Collins CH, Bottoli CBG. Nano-Liquid Chromatography in Pharmaceutical and Biomedical Research. Journal of Chromatographic Science 2013; 51(7):694-703. PMid:23585638. http://dx.doi. org/10.1093/chromsci/bmt023

75 Takeuchi T. Capillary columns in liquid chromatography. Analytical and Bioanalytical Chemistry 2003; 375(1):26-27. PMid:12520430.

76 Takeuchi T. Development of Capillary Liquid Chromatography. Chromatography 2005; 26(1):7-10.

77 Nguyen DTT, Guillarme D, Rudaz S, Veuthey JL. Fast analysis in liquid chromatography using small particle size and high pressure, Journal of Separation Science 2006; 29(12):1836-1848. PMid:16970187. http:// dx.doi.org/10.1002/jssc.200600189

78 MacNair JE, Patel KD, Jorgenson JW. UltrahighPressure Reversed-Phase Capillary Liquid Chromatography: Isocratic and Gradient Elution Using Columns Packed with 1.0- $\mu$ m Particles. Analytical Chemistry 1999; 71(3):700-708. PMid:9989386. http:// dx.doi.org/10.1021/ac9807013

$79 \mathrm{Wu}$ N, Clausen AM. Fundamental and practical aspects of ultrahigh pressure liquid chromatography for fast separations. Journal of Separation Science 2007; 30(8):1167-1182. PMid:17595952. http://dx.doi. org/10.1002/jssc.200700026

80 Jerkovich AD, Mellors JS, Jorgenson JW. The Use of Micron-Sized Particles in Ultrahigh-Pressure Liquid Chromatography. LC-GC Europe 2003; 16(6A):20-23.

81 Jorgenson JW. Capillary Liquid Chromatography at Ultrahigh Pressures. Annual Review of Analytical Chemistry 2010; 3(1):129-150. PMid:20636037. http:// dx.doi.org/10.1146/annurev.anchem.1.031207.113014

82 Xiang Y, Liu Y, Lee ML. Ultrahigh pressure liquid chromatography using elevated temperature. Journal of Chromatography A 2006; 1104(1-2):198202. PMid:16376355. http://dx.doi.org/10.1016/j. chroma.2005.11.118

83 Mellors JS, Jorgenson JW. Use of $1.5-\mu \mathrm{m}$ Porous Ethyl-Bridged Hybrid Particles as a Stationary-Phase Support for Reversed-Phase Ultrahigh-Pressure Liquid Chromatography. Analytical Chemistry 2004; 76(18):5441-5450. PMid:15362905. http://dx.doi. org/10.1021/ac049643d

84 Cintron JM, Colon LA. Organo-silica nano-particles used in ultrahigh-pressure liquid chromatography. Analyst 2002; 127(6):701-704. http://dx.doi. org/10.1039/b203236h

85 Muhlen CV, Lancas FM. Cromatografia unificada. Quimica Nova 2004; 27(5):747-753. http://dx.doi. org/10.1590/S0100-40422004000500014

86 Tong D, Bartle KD, Clifford AA. Principles and applications of unified chromatography. Journal of Chromatography A 1995; 703(1-2):17-35. http:// dx.doi.org/10.1016/0021-9673(94)01296-Q 